\title{
Flexible metabolic pathway construction using modular and divisible selection gene
} regulators

\author{
Rugbjerg, Peter; Myling-Petersen, Nils; Sommer, Morten Otto Alexander
}

Published in:

Metabolic Engineering

Link to article, DOI:

10.1016/j.ymben.2015.08.004

Publication date:

2015

Document Version

Peer reviewed version

Link back to DTU Orbit

Citation (APA):

Rugbjerg, P., Myling-Petersen, N., \& Sommer, M. O. A. (2015). Flexible metabolic pathway construction using modular and divisible selection gene regulators. Metabolic Engineering, 31, 189-197.

https://doi.org/10.1016/j.ymben.2015.08.004

\section{General rights}

Copyright and moral rights for the publications made accessible in the public portal are retained by the authors and/or other copyright owners and it is a condition of accessing publications that users recognise and abide by the legal requirements associated with these rights.

- Users may download and print one copy of any publication from the public portal for the purpose of private study or research.

- You may not further distribute the material or use it for any profit-making activity or commercial gain

- You may freely distribute the URL identifying the publication in the public portal

If you believe that this document breaches copyright please contact us providing details, and we will remove access to the work immediately and investigate your claim. 


\section{Flexible metabolic pathway construction using modular}

\section{and divisible selection gene regulators}

Authors:

Peter Rugbjerg ${ }^{\mathrm{a}}$ - petru@biosustain.dtu.dk

Nils Myling-Petersen ${ }^{\mathrm{a}}$ - nimyp@bio.dtu.dk

Morten O. A. Sommer ${ }^{\mathrm{a}}$ - msom@bio.dtu.dk

a) Novo Nordisk Foundation Center for Biosustainability, Technical University of Denmark

Kogle Allé 6, DK-2970 Hørsholm, Denmark

* Corresponding author 


\section{Abstract}

Genetic selections are important to biological engineering. Although selectable traits are limited, currently each trait only permits simultaneous introduction of a single DNA fragment. Complex pathway and strain construction however depends on rapid, combinatorial introduction of many genes that encode putative pathway candidates and homologs. To triple the utility of existing selection genes, we have developed divisible selection in Saccharomyces cerevisiae. Here, independent DNA fragments can be introduced and selected for simultaneously using a set of split hybrid transcription factors composed of parts from Escherichia coli LexA and Herpes simplex VP16 to regulate one single selectable phenotype of choice. Only when coexpressed, these split hybrid transcription factors promote transcription of a selection gene, causing tight selection of transformants containing all desired DNA fragments. Upon transformation, 94 percent of the selected colonies resulted strictly from transforming all three modules based on ARS/CEN plasmids. Similarly when used for chromosome integration, 95 percent of the transformants contained all three modules. The divisible selection system acts dominantly and thus expands selection gene utility from one to three without any genomic pre-modifications of the strain. We demonstrate the approach by introducing the fungal rubrofusarin polyketide pathway at a gene load of $11 \mathrm{~kb}$ distributed on three different plasmids, using a single selection trait and one yeast transformation step. By tripling the utility of existing selection genes, the employment of divisible selection improves flexibility and freedom in the strain engineering process. 
Keywords: Pathway construction, selection system, chromosomal integration, synthetic biology, split transcription factor

Abbreviations: AD: Activation domain, DBD: DNA-binding domain, TF:

Transcription factor, DS: Divisible selection 


\section{Introduction}

Metabolic engineering and synthetic biology research necessitates frequent introduction of several pieces of heterologous DNA to host strains at ever-increasing pace (Bornscheuer et al., 2012; Boyle and Silver, 2012; Keasling, 2012; Tyo et al., 2007). The rising complexity of reconstructed metabolic pathways demands high flexibility and freedom in these genetic manipulations to characterize the full space of variables.

Various approaches have been developed for combinatorial assembly of single or several pathway steps using yeast homologous recombination, software-guided cloning or simply large random clone assemblies (Genee et al., 2014; Gibson et al., 2010; Naesby et al., 2009; Shao et al., 2009). Systematic sampling of such biological variables as expression strength, codon usage, truncations and homologs is a strategy for developing metabolic pathways, where optimally performing strains may result from particular combinatorial clones. Freedom and flexibility in gene introduction methods are thus of importance.

Irrespective of gene introduction strategy, the selection genes that aid transformation with foreign DNA still follow the same principle of "one selectable trait, one selection gene". Consequently, selection genes are iteratively removed to allow recycled use when multi-gene systems are constructed, since selective traits are limited. Indeed, many strain construction methods are based on different approaches to recycling, using loop-out mechanisms based on recombinases or endogenous homologous recombination in increasingly streamlined implementations (Da Silva and 
Srikrishnan, 2012; Hegemann and Heick, 2011; Jensen et al., 2013; Mikkelsen et al., 2012; Siddiqui et al., 2014; Wingler and Cornish, 2011). Still, it would increase speed if more independent gene introductions were possible using the limited number of available selectable traits. Indeed, new selection genes are routinely identified to further expand strain construction freedom (Regenberg and Hansen, 2000; SolisEscalante et al., 2013). Whilst some are dominant in action, the recessive nature of most auxotrophic selection genes requires pre-modification of the receiving host strain by deletion of complementing prototrophic genes. The converse dominant selection genes typically involve antibiotics for maintenance of selection pressure, including harmful, costly agents such as bleomycin and hygromycin. Present-day pathway construction can thus yield strains requiring a mixture of selection pressures (Nielsen et al., 2014).

Saccharomyces cerevisiae is an important host for production of biofuels and commodity chemicals as well as structurally more advanced secondary metabolites, and the pathway complexities can only be expected to rise (Nielsen et al., 2013; Siddiqui et al., 2011).

As a modular and conceptually novel approach to multiply the utility of each selectable trait in S. cerevisiae, we here design and develop divisible selection based on split transcription factors (TFs). With divisible selection, three independent DNA fragments can be introduced simultaneously at the load of a single selection phenotype of choice. This is possible by dividing the regulation of selectable phenotypes into modules composed of hybrid split TFs. Exclusively when coexpressed, these reconstitute activation of a tight selection gene promoter, yielding 5 
efficient selection for all associated DNA fragments. The split TFs of divisible selection are designed to function dominantly and therefore expand the utility of an already functional selection gene from one to three, and possibly more, DNA fragments without any strain pre-modifications. Split divisible phenotypes could therefore take many applications within biological engineering. As a proof-ofprinciple for the system, we here employ divisible selection within metabolic engineering to reconstruct the Fusarium graminearum three-step polyketide pathway to rubrofusarin in S. cerevisiae by expression of the biosynthetic genes from three individual plasmids under one selectable trait.

\section{Methods and materials}

\subsection{Strains}

All characterization of the system efficiencies was performed in Saccharomyces cerevisiae CEN.PK2-1C (MATa; ura3-52; trp1-289; leu2-3,112; his3A 1; MAL2-8 ${ }^{C}$; $S U C 2)$. The three-step rubrofusarin polyketide pathway was introduced into $S$. cerevisiae CEN.PK2-1C pre-transformed with pRS413-npgA (CEN.PK2-1C-npgA) yielding the strains listed in Table 1.

All molecular cloning was performed using transformation into Escherichia coli XL1 chemically competent cells (Stratagene).

Table 1 Strains analyzed for ability to maintain plasmids for rubrofusarin production given the indicated method of selection based either on classical selection genes (cl) or divisible selection (ds) using a hybrid DNA-binding domain (DBD) and activation domain (AD). All strains were generated from the CEN.PK2-1C-npgA parent strain.

6 


\begin{tabular}{|l|l|l|}
\hline Strain & Pathway plasmids & Selective gene \\
\hline cl-rub & pRS416-PKS12 & URA3 \\
\cline { 2 - 3 } & pRS414-aurZ & TRP1 \\
\cline { 2 - 3 } & pRS415-aurJ & LEU2 \\
\hline ds-rub & pDS1-PKS12 & $d s 1-U R A 3$ \\
\cline { 2 - 3 } & & \\
\cline { 2 - 3 } & pDS2-aurZ & $d s 2-D B D$ \\
\cline { 2 - 3 } & & \\
\cline { 2 - 3 } & pDS3-aurJ & $d s 3-A D$ \\
\hline
\end{tabular}

\subsection{Materials}

Unless otherwise stated, reagents were purchased from Sigma-Aldrich. Synthetic complete (SC) medium was prepared with $1.4 \mathrm{~g} / \mathrm{L}$ synthetic complete drop-out mix lacking uracil, tryptophan, leucine and histidine (Y2001), $6.7 \mathrm{~g} / \mathrm{L}$ yeast nitrogen base without amino acids (Y0626) and $20 \mathrm{~g} / \mathrm{L}$ D-glucose, $\mathrm{pH}$ standardized to $5.6 . \mathrm{Cu}^{2+}$ for gene induction was added from a stock solution of $100 \mathrm{mM} \mathrm{CuSO}$. When SC was supplemented with additional amino acids, $60 \mathrm{mg} / \mathrm{L}$ leucine, $20 \mathrm{mg} / \mathrm{L}$ uracil, $20 \mathrm{mg} / \mathrm{L}$ histidine- $\mathrm{HCl}$ and $20 \mathrm{mg} / \mathrm{L}$ tryptophan was added. Oligonucleotides were purchased from Integrated DNA Technologies.

\subsection{Construction of plasmids}

Plasmids were assembled by uracil-excision (USER) cloning of purified PCR fragments, except for pDS2-aurZ, which was cloned by Gibson assembly of a purified PCR fragment into a pDS2 vector linearized with SmaI. Gibson assembly was performed using 2x Gibson assembly master mix (New England Biolabs) according to 
the manufacturer's protocol. The general method for USER cloning was based on agarose gel-purification of the PCR products amplified with DNA polymerase X7 (Nørholm, 2010). These were mixed and incubated in an equimolar $20 \mu \mathrm{L}$ reaction with $0.5 \mu \mathrm{L}$ USER enzyme (New England Biolabs) and 0.5 $\mu \mathrm{L}$ DpnI FastDigest (Thermo Scientific) in FastDigest buffer at 37 degrees C for 1-2 hours. Following 25 subsequent minutes at room temperature, $2.5 \mu \mathrm{L}$ reaction was transformed into chemically competent E. coli. Correctly cloned plasmids were identified using restriction analysis and DNA sequencing. The detailed use of oligonucleotides for assembly of all plasmids and origin of parts are listed in supplementary material.

\subsection{Plasmids}

All plasmids developed and characterized for divisible selection are listed in Table 2 and all plasmids for production of rubrofusarin pathway are listed in Table 3.

Table 2 Plasmids for use in divisible selection and conventionally selected plasmids (pRS41x) used for comparison. All vectors propagate in S. cerevisiae using the indicated method and in E. coli using pUC origin of replication and ampicillin resistance. NLS abbreviates nuclear localization signal. Unless otherwise stated, gene source is $S$. cerevisiae.

\begin{tabular}{|c|c|c|c|c|c|}
\hline $\begin{array}{l}\text { Plasmid } \\
\text { name }\end{array}$ & $\begin{array}{l}\text { Selection gene } \\
\text { promoter }\end{array}$ & $\begin{array}{l}\text { Selection gene } \\
\text { ORF }\end{array}$ & $\begin{array}{l}\text { Selection gene } \\
\text { terminator }\end{array}$ & $\begin{array}{l}\text { Propagation } \\
\text { in yeast by }\end{array}$ & Reference \\
\hline pDS1U & \multirow{3}{*}{$8 \mathrm{op}_{\text {lexA }}-\mathrm{SPO13}$} & \multirow{3}{*}{ URA3 } & \multirow{3}{*}{ K. lactis URA3 } & CEN/ARS & This study \\
\hline pDS1Um & & & & 2 micron & This study \\
\hline $\begin{array}{l}\text { pDS1U- } \\
\mathrm{X} 2\end{array}$ & & & & $\begin{array}{l}\text { Chromosome } \\
\text { integration }\end{array}$ & This study \\
\hline
\end{tabular}




\begin{tabular}{|c|c|c|c|c|c|}
\hline pDS1H & $8 \mathrm{op}_{\text {lexA }}-S P O 13$ & HIS3 & K. lactis URA3 & CEN/ARS & This study \\
\hline pDS2 & \multirow{3}{*}{$\begin{array}{l}\text { A. gossypii } \\
\text { TEF1 }\end{array}$} & \multirow{3}{*}{$\begin{array}{l}N L S- \\
\text { E. coli lexA- } \\
\text { krevl }\end{array}$} & \multirow{3}{*}{$\begin{array}{l}\text { A. gossypii } \\
\text { TEF1 }\end{array}$} & CEN/ARS & This study \\
\hline pDS2m & & & & 2 micron & This study \\
\hline pDS2-X3 & & & & $\begin{array}{l}\text { Chromosome } \\
\text { integration }\end{array}$ & This study \\
\hline pDS3 & \multirow{3}{*}{$\begin{array}{l}\text { A. gossypii } \\
\text { TEF1 }\end{array}$} & \multirow{3}{*}{$\begin{array}{l}N L S- \\
\text { H. simplex } \\
\text { VP16(AD)- } \\
\text { ralGDS }\end{array}$} & \multirow{3}{*}{$\begin{array}{l}\text { A. gossypii } \\
\text { TEF1 }\end{array}$} & ARS/CEN & This study \\
\hline pDS3m & & & & 2 micron & This study \\
\hline pDS3-X4 & & & & $\begin{array}{l}\text { Chromosome } \\
\text { integration }\end{array}$ & This study \\
\hline $\mathrm{pDS} 1.2 \mathrm{U}$ & $8^{8 o p_{l e x A}-S P O 13}$ & URA3 & K. lactis URA3 & ARS/CEN & This study \\
\hline pDS1.3U & $40 p_{l e x A}-S P O 13$ & K. lactis URA3 & K. lactis URA3 & ARS/CEN & This study \\
\hline $\begin{array}{l}\text { pRS414- } \\
\text { empty }\end{array}$ & \multicolumn{3}{|l|}{ TRP1 } & ARS/CEN & $\begin{array}{l}\text { (Sikorski and } \\
\text { Hieter, 1989) }\end{array}$ \\
\hline $\begin{array}{l}\text { pRS415- } \\
\text { empty }\end{array}$ & \multicolumn{3}{|l|}{ LEU2 } & ARS/CEN & $\begin{array}{l}\text { (Sikorski and } \\
\text { Hieter, 1989) }\end{array}$ \\
\hline $\begin{array}{l}\text { pRS416- } \\
\text { empty }\end{array}$ & \multicolumn{3}{|l|}{$U R A 3$} & ARS/CEN & $\begin{array}{l}\text { (Sikorski and } \\
\text { Hieter, 1989) }\end{array}$ \\
\hline
\end{tabular}

Table 3 Divisible selection plasmids developed to reconstruct the $F$. graminearum $(F g)$ rubrofusarin polyketide pathway in S. cerevisiae CEN.PK2-1C-npgA based on uracil prototrophy and benchmark plasmids with the same pathway genes and classical auxotrophic selection genes. The respective pathway open reading frames (ORF) were expressed with the indicated promoter and terminators from S. cerevisiae. All plasmids propagate in S. cerevisiae based on a CEN/ARS origin.

\begin{tabular}{|l|l|l|l|}
\hline $\begin{array}{l}\text { Plasmid } \\
\text { name }\end{array}$ & $\begin{array}{l}\text { Pathway cassette } \\
\text { (promoter-ORF-terminator) }\end{array}$ & Selective gene & Reference \\
\hline pDS1U- & p $_{\mathrm{CUP1}-F g P K S 12-\mathrm{t}_{\mathrm{ADH} 1}}$ & $d s 1-U R A 3$ & This study \\
\hline
\end{tabular}




\begin{tabular}{|c|c|c|c|}
\hline PKS12 & & & \\
\hline $\begin{array}{l}\text { pDS2- } \\
\text { aurZ }\end{array}$ & $\mathrm{p}_{\mathrm{TEF} 1}-$ F gaurZ- $\mathrm{t}_{\mathrm{ENO} 2}$ & $d s 2-D B D$ & This study \\
\hline pDS3-aurJ & $\mathrm{p}_{\mathrm{GPD} 1}-$ FgaurJ-t $\mathrm{t}_{\mathrm{CYC} 1}$ & $d s 3-A D$ & This study \\
\hline $\begin{array}{l}\text { pRS416- } \\
\text { PKS12 }\end{array}$ & $\mathrm{p}_{\mathrm{CUP} 1}-F g P K S 12-\mathrm{t}_{\mathrm{ADH} 1}$ & URA3 & $\begin{array}{l}\text { (Rugbjerg et al., } \\
\text { 2013) }\end{array}$ \\
\hline $\begin{array}{l}\text { pRS414- } \\
\text { aurZ }\end{array}$ & $\mathrm{p}_{\mathrm{TEF1} 1}-$ FgaurZ-t $\mathrm{t}_{\mathrm{ENO} 2}$ & TRP1 & $\begin{array}{l}\text { (Rugbjerg et al., } \\
\text { 2013) }\end{array}$ \\
\hline $\begin{array}{l}\text { pRS415- } \\
\text { aurJ }\end{array}$ & $\mathrm{p}_{\mathrm{GPD} 1}-$ FgaurJ-t $\mathrm{t}_{\mathrm{CYCl}}$ & LEU2 & $\begin{array}{l}\text { (Rugbjerg et al., } \\
\text { 2013) }\end{array}$ \\
\hline $\begin{array}{l}\text { pRS413- } \\
\text { npgA }\end{array}$ & $\mathrm{p}_{\mathrm{PYK} 1}-n p g A-\mathrm{t}_{\mathrm{TEF} 1}$ & HIS3 & $\begin{array}{l}\text { (Rugbjerg et al., } \\
\text { 2013) }\end{array}$ \\
\hline
\end{tabular}

All plasmids constructed in this study will be deposited at the Addgene repository.

\subsection{Transformation of S. cerevisiae}

S. cerevisiae was transformed using lithium acetate-type transformation based on a high-efficiency protocol (Gietz and Schiestl, 2007) with a few minor adjustments: A single colony was pre-cultured overnight at 30 degrees C, $250 \mathrm{rpm}$ shaking in $10 \mathrm{~mL}$ yeast peptone dextrose (YPD) medium. On the day of transformation, individual main cultures of $10 \mathrm{~mL}$ YPD were each inoculated to $\mathrm{OD}_{600}=0.20$ and cultured for 4 hours at 30 degrees C, $250 \mathrm{rpm}$ shaking. The cell pellet of each was used per transformation. For chromosomal integration, to liberate $3 \mu \mathrm{g}$ of each integration construct from its vector, $5 \mu \mathrm{g}$ of each the integration vector were first linearized with SmiI FastDigest (Thermo Scientific) in a $40 \mu \mathrm{L}$ reaction with 1x Fastdigest buffer for 2 hours at 37 degrees $\mathrm{C}$ and purified with a PCR clean-up kit (Macherey-Nagel) with 
elution into $20 \mu \mathrm{L} \mathrm{H} \mathrm{H}_{2} \mathrm{O}$. The exact $\mathrm{PEG}_{3350}$ concentration was critical for good transformation efficiencies, and test titrations of every $50 \% \mathrm{PEG}_{3350}$ batch were made to assure this by varying the volume of the batch $+/-10$ percent in 2 percent point increments. The resultant optimum was used through compensation by adding less/more $\mathrm{H}_{2} \mathrm{O}$ to the transformation mixture. Gentle final resuspension of the transformed cells in $\mathrm{H}_{2} \mathrm{O}$ was also important for the transformation efficiency: After removal of the transformation mix supernatant and addition of $\mathrm{H}_{2} \mathrm{O}$, the sample was left to recover at room temperature for ten minutes prior to gentle resuspension using a pipette, first mildly tapping on the cell pellet before slowly pipetting it up and down two-three times. For chromosomal integrations this recovery was extended to twenty minutes. Each transformation was plated on one or two plates of synthetic complete (SC) medium lacking the appropriate selection nutrient. Colonies were counted following 65 hours of incubation at 30 degrees C. All transformations described were carried out in three or six replicates and no replicates were conducted in parallel.

\subsection{Reconstruction of fungal polyketide pathway by divisible selection}

S. cerevisiae CEN.PK2-1C-npgA was first constructed through transformation of $S$. cerevisiae CEN.PK2-1C with pRS413-npgA. Next, this strain was transformed with the plasmids pDS1U-PKS12, pDS2-aurZ and pDS3-aurJ (Table 2) in a single transformation step as described in section 2.5. After heat shock, the transformed cells were allowed to recover in YPD for 1 hour at room temperature prior to removal of YPD and plating. The exact influence of recovery based on YPD relative to $\mathrm{H}_{2} \mathrm{O}$ was not evaluated. Selection of transformants was performed on SC -uracil plates. 
Following incubation at 30 degrees C, individual transformants were re-plated to SC uracil -histidine plates with $100 \mu \mathrm{M} \mathrm{Cu}^{2+}$ to induce the pathway and also select for maintenance of the previously transformed pRS413-npgA plasmid.

\subsection{Extraction of $S$. cerevisiae DNA and PCR validation of presence of $d s$ modules}

A single colony was dissolved in $100 \mu \mathrm{L}$ solution of $200 \mathrm{mM}$ lithium-acetate, $1 \%$ sodium dodecyl sulfate and incubated at $70 \mathrm{deg}$. C for 5 minutes. $300 \mu \mathrm{L} 99 \%$ ethanol was added and the cells were pelleted by centrifugation at 15,000 g, 3 minutes and washed in $400 \mu \mathrm{L} 70 \%$ ethanol. The cells were again pelleted and resuspended in $100 \mu \mathrm{L} \mathrm{H}_{2} \mathrm{O}$, after which the cells were pelleted at 15,000 g for 15 seconds. From the supernatant, $1 \mu \mathrm{L}$ was used as template DNA for a PCR to validate presence of the three divisible selection plasmids using primers, which specifically anneal to unique parts of the ds modules: ds 1: P55 + ID399 (expected size: 364 bp), ds2: P191 + P283 (expected size: 1239 bp) and ds3: P111 + P230 (expected size: 608 bp) (sequences in supplementary material Table S3). Site-specific integration by double-crossover on $S$. cerevisiae chromosome $\mathrm{X}$ was tested as devised in the Easyclone concept (Jensen et al., 2013) using the primer 5'-AGGTCGCUCATCGCACGC together with the following primers, which all anneal to loci immediately upstream of the three respective homologous recombination target areas: $\mathrm{X}-2$ : 5'-

TGCGACAGAAGAAAGGGAAG (expected size: 700 bp), X-3: 5'-

TGACGAATCGTTAGGCACAG (expected size: 887 bp), X-4: 5’-

CTCACAAAGGGACGAATCCT (expected size: 810 bp).

And similarly for the downstream target areas using the primer 5'ACCCAATTCGCCCTATAGTGAGTCG together with the chromosome-specific 
primers X-2: 5'- GAGAACGAGAGGACCCAACAT (expected size: 1063 bp), X-3: 5'- CCGTGCAATACCAAAATCG (expected size: 757 bp), X-4: 5'GACGGTACGTTGACCAGAG (expected size: 746 bp)

\section{Results}

\subsection{Design of divisible selection}

To develop effective divisible selection in S. cerevisiae, we identified five important system criteria. 1) Stringency: Selection should be highly efficient for all associated parts and disallow false selection at incomplete uptake of all parts. 2) Modularity: The ability to divide a selection phenotype into multiple co-dependent entities should be independent of the actual selection phenotype i.e. also function when plugging in a different selection gene ORF. 3) Dominance: Pre-adaptation of the host strain should not be necessary in order to use divisible selection instead of the corresponding single selection gene. 4) Stability: The system should use few endogenous parts from the host strain to minimize risks of recombination and crosstalk. 5) Scalability: The concept should be scalable towards wider division, such as split of TFs into additional components or simultaneous use of multiple, orthogonal TF networks. 
Classical selection Divisible selection

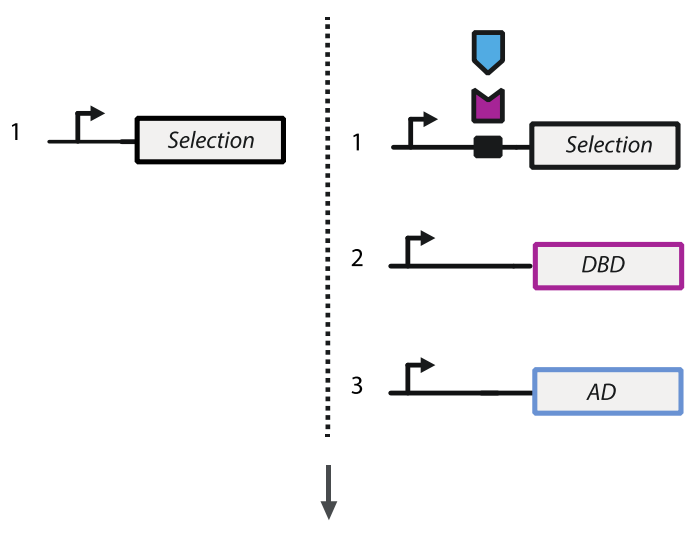

1 SELECTION PHENOTYPE

Figure 1 Design of divisible selection in S. cerevisiae. Unlike classical selection, divisible selection expands a single selectable trait to introduce multiple DNA fragments using split transcription factors. The selection gene is activated by the fully reconstituted transcription factor based on a hybrid DNAbinding domain (DBD) and hybrid transcriptional activation domain (AD).

To meet these criteria, we designed divisible selection as three individually expressed modules (Fig. 1) that we could link physically to three independent DNA fragments (plasmids). The modules consist of: DS1) A selection gene ORF driven by a promoter, tightly responsive to: DS2) A DNA-binding protein fused to a proteininteracting domain, cognate to: DS3) Another protein-interacting domain fused to a transcription activation domain. The TF-based approach would ensure modularity since other selection gene ORFs can be swapped in and out. To achieve high stringency, we engineered a synthetic promoter based on the SPO13 promoter, which 
features a mitotic UME6 repressor-binding site to suitably abolish leaky expression as previously utilized (Vidal et al., 1996). UME6 represses SPO13 promoter activity in mitotic cells (Mitchell, 1994), thus rendering the TF response tighter. This is important since even very low expression of auxotrophic selection genes typically reconstitute prototrophy.

To develop divisible selection to act dominantly on existing selection phenotypes, we engineered the split TFs using proteins heterologous to $S$. cerevisiae to avoid interactions with endogenous repressors or promoters. Finally, we expressed the split TF modules from promoters not present in the $S$. cerevisiae genome to limit unintended recombination.

\subsection{Detailed design composition}

The divisible selection module $d s 1-U R A 3$ was engineered with the classical URA3 gene under control of a 157 bp SPO13 promoter fragment (Fig 2A). Upstream of the promoter fragment, we inserted four natural and synthetic DNA-binding sites specific for Escherichia coli LexA at various in vitro-based $\mathrm{K}_{\mathrm{d}}$ values down to $0.810^{-9} \mathrm{M}$ (Zhang et al., 2010) to achieve high saturation as soon as few LexA proteins enter the cell nucleus. As terminator, the URA3 terminator from Klyveromyces lactis was used. 
A

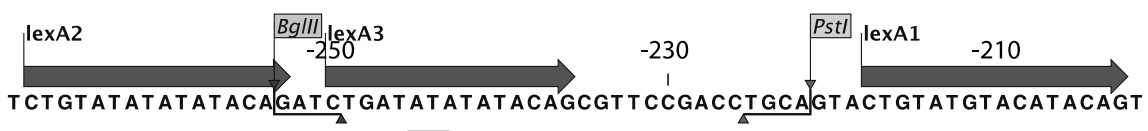

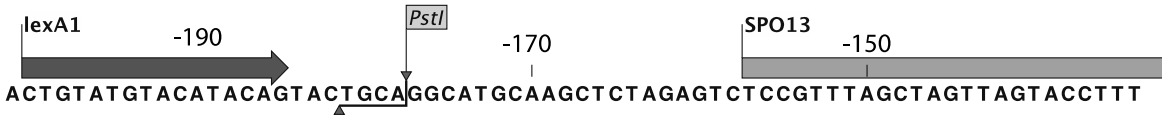

SPO13 UME6

\begin{tabular}{rrr}
-130 & -90 & -90 \\
\hline
\end{tabular}

GCACGGAAATGTAT TAAT TAGGAGTATATTGAGAAATAGCCGCCGACAAAAAGGAAGTCTCATAAAAG

SPO13

$\frac{1}{\text { TGTCTAACAGACAAT TAGCGCAATAAGAAGAAAGAAAACGGATTGAAGTTGAGTCGAGAATAATT ATG }}$

B
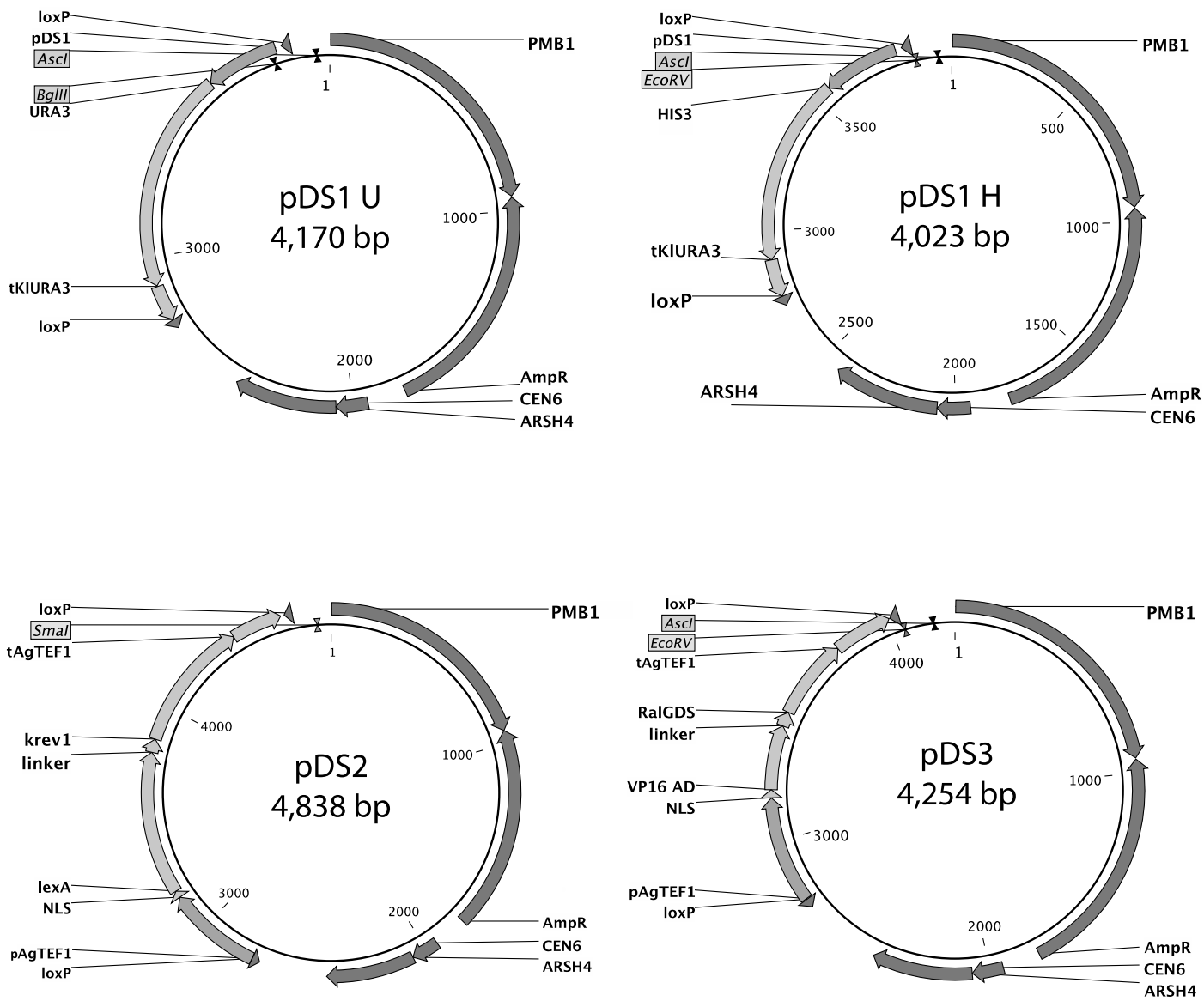

Figure 2. Sequence composition of core divisible selection modules and their vectors. A) DNA sequence of the hybrid DS1 promoter featuring elements of the S. cerevisiae SPO13 promoter and upstream different LexA-binding sites. B) Plasmid maps showing the parts orchestration for the three main divisible selection modules and their propagating ARS/CEN vectors. 
The $d s 2-D B D$ module consists of the $E$. coli LexA DNA-binding repressor in an Nterminal fusion to a nucleus localization sequence (NLS). Using an RSNQTSLYKKAGSAAAPFT linker, LexA is C-terminally fused to a Krev-1 (Rap1A) protein, known for its functional protein interaction to RalGDS (Herrmann et al., 1996). For expression of the hybrid protein, a heterologous TEF1 promoter and terminator pair from Ashbya gossipy $(\mathrm{Ag})$ was chosen.

The $d s 3-A D$ module was an N-terminal fusion of NLS to the potent activation domain of Herpes simplex VP16 linked C-terminally to RalGDS using an SNQTSLYKKAGSAAAPFT linker. Expression was driven from the AgTEF1 promoter and terminator.

Each module was inserted in a CEN/ARS-propagated vector derived of pRS416, but free of yeast selection genes (Fig. 2B). loxP sites flank all modules to add optional compatibility to recycling systems using cre recombinase-based recycling of selection genes. 


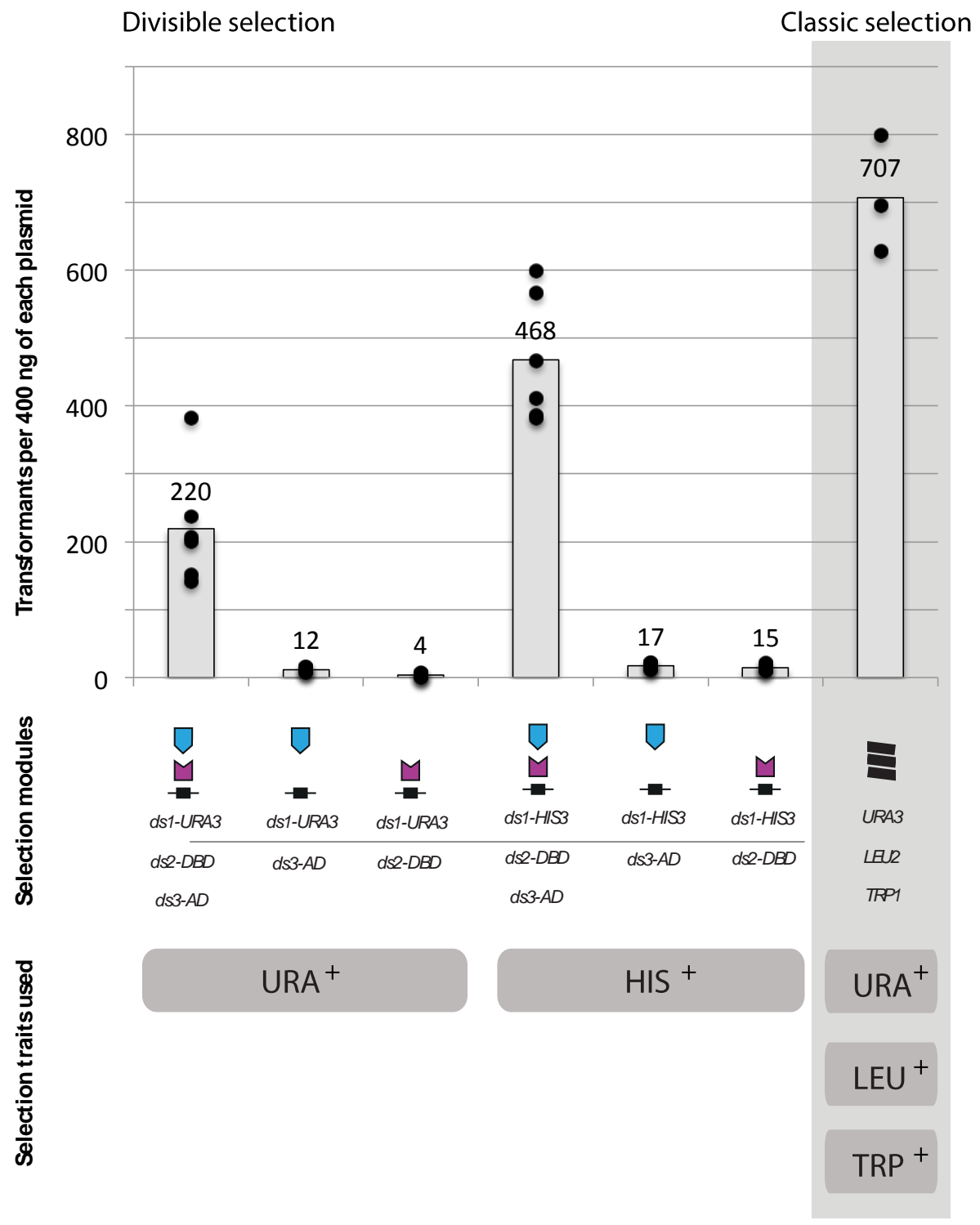

Figure 3 Tight selection of three plasmids under one selectable trait by divisible selection. Transformation efficiencies (average CFU per $400 \mathrm{ng}$ of each plasmid) in S. cerevisiae CEN.PK2-1C transformed with incomplete or complete divisible selection modules $\left(d s 1-H I S 3 / U R A 3^{-}-, d s 2-D B D\right.$ $\square$ and ds3-AD $\square$ ) under selection on SC -ura or SC -his, or SC -ura, -trp, -leu (with control classic selection genes). CFUs were counted following 65 hours at 30 deg. C. Black points show values from individual replicate transformations $(n=6$, except for classical plasmids where $n=3)$. 


\subsection{Selection for three different plasmids activating a single selection phenotype}

To characterize the performance of divisible selection, all three modules $d s l, d s 2$ and $d s 3$ were simultaneously transformed into the ura3-deficient $S$. cerevisiae CEN.PK21C, and an average of 220 transformants per $400 \mathrm{ng}$ of each plasmid formed colonies after 3 days incubation on SC -ura (Fig. 3). Theoretically, false activation of the $d s 1$ module in absence of $d s 2$ (DBD) and/or $d s 3$ (AD) has potential to cause false-positive selection. Thus, the vectors containing $d s 1$ and $d s 3$ were used as negative transformation control to specifically characterize possible transcriptional activity from the hybrid DBD protein and selection gene ORF. Following 3 days, an average of 4 colonies were observed after transformation with $d s 1-U R A 3$ and $d s 2$, whereas 12 colonies were observed with $d s 1-U R A 3$ and $d s 3$, indicating that the selection system was tight with a $94 \%$ occurrence of true-positive transformants (Fig. 3). The few false-positive colonies were generally smaller than the true-positive colonies. The efficiency was further compared to transformation of three plasmids (pRS414, pRS415 and pRS416) selected for using the classical auxotrophic selection genes LEU2, TRP1 and URA3 to benchmark the general co-transformation efficiency. These plasmids resulted in an average 3-fold higher colony count at 707 transformants per $400 \mathrm{ng}$ of each three plasmids. The reason for this advance in efficiency was not apparent, but we suspected suboptimal transcriptional activation of $d s 1$ to be responsible. To modify this however, it would be important to not simultaneously increase the frequency of false-positive transformants and we concluded the resulted transformation efficiency to be satisfactory for most applications. 
A few preliminary constructs of the $d s 1$ module were also evaluated in slightly modified pRS41x-type vectors, testing fewer lexA binding sites and a heterologous $K$. lactis URA3 sequence instead of the $S$. cerevisiae URA3. Remarkably, while no difference in colony formation was seen at 3 days, a considerate number of falsepositive transformants formed colonies when using fewer binding sites and the $K$. lactis URA3 following prolonged incubation at 30 degrees $\mathrm{C}$ for 6 days (supplementary material).

\subsection{Modular exchange of selection phenotype from Ura ${ }^{+}$to $\mathrm{His}^{+}$}

To test the modularity of divisible selection and its ability to expand other selectable traits, we exchanged the URA3 ORF in $d s 1$ with the ORF of HIS3 from S. cerevisiae. Transformation with the three modules $d s 1-H I S 3, d s 2$ and $d s 3$ resulted in an average of 468 transformants after 3 days incubation. 17 transformants resulted from the control transformation with only $d s 1-H I S 3$ and $d s 3$, relative to 15 colony-forming cells with $d s 1-H I S$ and $d s 2$, indicating that the system robustly could shift to a different prototrophy (Fig. 3). Thus, the simple exchange of the selection phenotype demonstrates the versatility of the concept, and indicates that more selectable traits could be modularly divided. 


\subsection{Divisible selection with copy number-fluctuating plasmids (2-micron)}

Elevation of gene copy number can lead to increased formation of the metabolic products. To this end, the multi-copy 2-micron yeast plasmid is sometimes utilized, although its copy number varies considerably per cell (Da Silva and Srikrishnan, 2012; Jensen et al., 2013). To test how this plasmid type functions with the divisible selection system, we cloned $d s 1 U, d s 2$ and $d s 3$ into three plasmids with 2-micron origins. The plasmids were transformed simultaneously, while omitting the $d s 2$ plasmid as a control for false-positive transformants.

Following three days of incubation, an average of 327 transformants (std. dev. $=85$ ) were visible, relative to the false-positive control omitting the $d s 2$ module, which reached 30 visible transformants $($ std. dev. = 4). However, on day four more transformants appeared on especially the false-positive control plates, and on day five this number reached a proportion of around $50 \%$ the number of true-positive transformants. This high occurrence of false-positive transformants could be a consequence of selecting for amplification of the $d s 1 U$ plasmid copy number, allowed by the 2-micron origin over time. Such an effect is similar to plasmid amplification methods that utilize weakly expressed selection genes (Chen et al., 2012; Erhart and Hollenberg, 1983): Elevated URA3 baseline expression may eventually provide enough URA3 to reconstitute the $\mathrm{Ura}^{+}$phenotype in absence of $d s 2$ or $d s 3$. Accordingly, the copy-number fluctuation of the 2-micron plasmid renders it a suboptimal plasmid system for use with the divisible selection system compared to the centromeric plasmids. 


\subsection{Three simultaneous chromosomal integrations selected under one selection}

phenotype

A

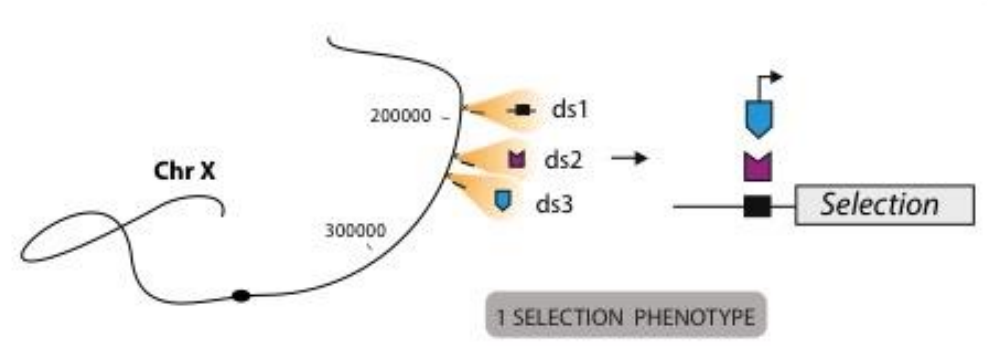

B

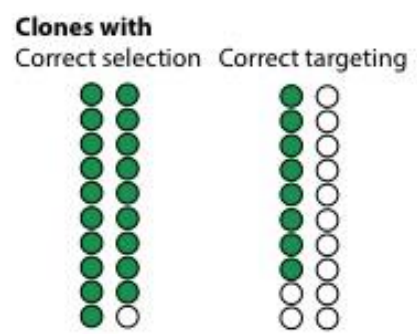

Figure 4 Chromosomal integration of three DNA fragments at different sites activating a single selection phenotype. A) Simultaneous gene insertion at three chromosome X loci in S. cerevisiae reconstituting a split hybrid transcription factor to activate a single selection phenotype. Genomic positions are correct relative to the two base-pair marks shown, while the remaining chromosome is overdrawn, B) PCR validation subsequently resulted in $95 \%$ clones with all three $d s$ modules present (correct selection), and $40 \%$ of the clones showed targeting at the intended chromosomal location.

Chromosomal integration of genes is frequently used in metabolic engineering due to the copy number stability offered, e.g. alleviating selection for maintenance. Thus, to test whether the utility of a selection phenotype also could be tripled for chromosomal integration, we cloned the three ds modules $d s 1 U, d s 2$ and $d s 3$ into three integration vectors from the Easyclone concept (Jensen et al., 2013). The Easyclone vectors target three distinct loci on S. cerevisiae chromosome X (Mikkelsen et al., 2012) through homologous recombination of $0.5 \mathrm{~kb}$ upstream and downstream flanking sequences (Fig. 4A). Such simultaneous integration at three distinct loci is rarely reported, which may also be due to the fact that a single cell should both take up three different DNA fragments and integrate each of them correctly. Since high 
transformation efficiency would be required to obtain three simultaneous integrations, a generous amount of DNA (3 $\mu \mathrm{g}$ of each $d s$ module) was applied during transformation. Following three days' incubation, 20 transformants were isolated on SC plates lacking uracil. First, we assayed the selection stringency of the resulting clones. PCR on gDNA extracted from the transformants revealed presence of $d s 1$ and $d s 2$ in all twenty colonies, whereas $d s 3$ could be confirmed in nineteen, leading to an overall estimated efficiency of $95 \%$ (Fig. 4B). Further, the single transformant lacking $d s 3$ appeared to grow much slower when re-streaked to selective medium. The efficiency of chromosomal targeting in yeast not only depends on the performance of the selection mechanism, but may also depend on the specific integration constructs and target loci. Next, we tested this targeting efficiency by PCR using locus-specific primers. In $40 \%$ of our transformants, site-specific insertion of all three $d s$ modules could be verified by PCR. Simultaneous gene targeting at three loci has previously been shown with $44 \%$ targeting efficiency using classical auxotrophic selection genes (Jensen et al., 2013), which thus agreed very well.

\subsection{Proof-of-principle construction of fungal polyketide pathway}

To prove the divisible selection principle for introduction of a multi-gene metabolic pathway, we chose a fungal secondary metabolic pathway as test case. Into each of the three pDS vectors, we inserted one of the three genes known to reconstruct the pathway leading from endogenous acetyl CoA and malonyl CoA to rubrofusarin PKS12, aurZ and aurJ (Rugbjerg et al., 2013). These genes encode respectively an iterative type I polyketide synthase, dehydrogenase and O-methyltransferase (Fig. 
5A). Since the host yeast strain harbored a gene encoding a general polyketide synthase-activating phosphopantetheinyl transferase NpgA expressed from a fourth CEN/ARS plasmid (pRS413-npgA), successful gene introduction would result in heterologous rubrofusarin production. This tricyclic polyketide is visible as a distinct orange-brown pigment. Following transformation, six transformants formed colonies. These were evaluated for production by plating on an induction agar plate with 100 $\mu \mathrm{M} \mathrm{Cu}^{2+}$, and yellow pigmentation indicated the successful activity of the metabolic pathway as compared to a classically selected pathway strain and a negative control strain (Fig. 5B). Further, to verify introduction of all three plasmids, specific PCRs were performed on extracted DNA from three randomly chosen transformants and the resulting bands confirmed presence of all plasmids (example Fig. 5C). Accumulation of the two pathway intermediates result in yellow-toned though distinguishable pigmentation, for which reason PCR validation was particularly important as final proof of successful gene introduction.

Since five simultaneously propagated centromeric plasmids can cause considerate cytotoxicity (Futcher and Carbon, 1986), this was further evaluated in a strain with four empty CEN/ARS plasmids. Without selection, this strain did show loss of plasmids in long-term cultures, but normal cell morphology and exponential growth rate (supplementary material). With selection, the stability of the four CEN/ARS plasmids carrying the rubrofusarin pathway was further tested in ten randomly picked colonies following a 30-generation liquid cultivation. PCR on unique plasmids was confirmative for all four plasmids in all ten colonies, whereas maintained pathway function was indicated through visual inspection of cell pigmentation (supplementary material). 

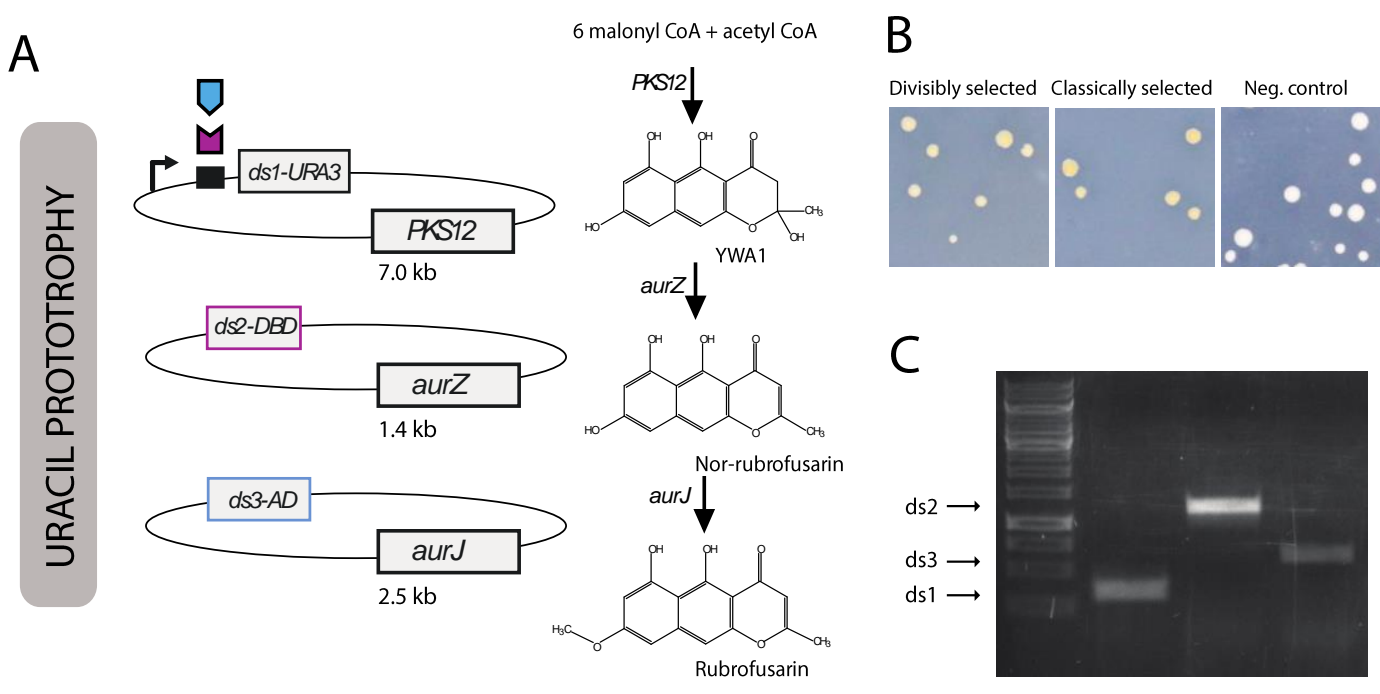

Figure 5 Introduction of a three-gene metabolic pathway in S. cerevisiae on three individual plasmids through a single transformation and selectable trait. A) The biosynthetic genes for the $F$. graminearum rubrofusarin polyketide pathway were introduced on each of the three divisible selection vectors to catalyze the indicated reactions from acyl-CoA precursors to rubrofusarin. B) Platings of $S$. cerevisiae strains with the rubrofusarin pathway maintained through i) one divisible selection phenotype $\left(\mathrm{Ura}^{+}\right)$ii) three classical selection phenotypes $\left(\mathrm{Ura}^{+}, \mathrm{Leu}^{+}, \mathrm{Trp}^{+}\right)$and iii) a reference CEN.PK2-1C strain with empty plasmids. Plated on respectively SC -ura-his, SC-ura-his-leu-trp and SC -ura-his-leu-trp agar plates, all with $100 \mu \mathrm{M} \mathrm{Cu}^{2+}$ for pathway induction. C) Verification of presence of all three divisible selection plasmids after transformation with rubrofusarin pathway by specific PCRs on genomic DNA. PCRs loaded for each of the three divisible selection plasmids yielding the expected and indicated band sizes. GeneRuler $1 \mathrm{~kb}$ loaded as size ladder.

\section{Discussion}

Divisible selection is a new modular concept for selection of several physically independent DNA fragments using the same selective trait. This yields increased 
strain construction freedom since multiple, independent DNA can be introduced utilizing only one selectable phenotype. Such divisible selection is especially relevant in strains with limited selectable traits. Due to the modularity of the concept, flexibility is added to the strain engineering process in several aspects. Specifically, we have shown that the particular phenotype can be modularly swapped by only exchanging the selection gene ORF of the system $(d s l)$. Further, while all three modules are essential, they need not all carry a pathway gene. For example, it is possible to utilize only the $d s 2$ and $d s 3$ modules (containing the hybrid DBD and AD parts) for production genes and co-transform $d s 1$ as phenotypic decider to control selection phenotype conveniently without sub-cloning. Such flexibility could become important in saving time needed to make pathway genes compatible with new host strains e.g. when testing performance in genetics-limited industrial strains or combining two individually tested segments of a long metabolic pathway.

$d s 1$ is the critical component to the performance of the system by carrying the full selection gene ORF. As shown, there is a high probability that a single picked clone will be a correct transformant, since false-positive transformants on average occurred at 4-6 percent of the positively transformed clones. This low percentage could have been overestimated slightly from the assay method of omitting one of the split hybrid TF modules: due to the high co-transformation efficiency in S. cerevisiae, it is possible that a fraction of these false-positive cells would also take up additional plasmids if available. Whereas the plasmid copy number is maintained stably through cell divisions by the CEN sequence (Clarke and Carbon, 1985), it is possible that the few false-positive transformants may have arisen from uptake of multiple $d s 1$ copies 26 
during transformation. In contrast the copy number variation of 2-micron plasmids led to an increased number of false positives. This episomal plasmid fluctuates considerably in copy number due to its propagation method (Mead et al., 1986) and thus also appears less ideal for metabolic engineering in some regards (Jensen et al., 2013). With targeted chromosomal integration, the introduction of a single copy of each $d s$ module likely resulted in the high selection stringency observed and similar to that observed with the CEN/ARS plasmids.

The proof of principle by introduction of a three-gene fungal polyketide pathway demonstrates the potential of divisible selection to introduce metabolic pathways under a single selection phenotype. The polyketide pathway was chosen as a relatively large extreme in terms of size (total of $11 \mathrm{~kb}$ ) and the size mainly resulted from the $7 \mathrm{~kb}$ polyketide synthase cassette. Since divisible selection depends on cotransformation of all DNA units in a single step, good transformation efficiency is important. For more extreme sizes, it is therefore possible that the use of simple lithium-acetate transformation methods will prove limiting, calling for methods suited for large DNA fragments. Ideally, future systems should improve the transformation colony formation rate compared to classical selection genes, e.g. through manipulation of the output promoter to increase responsiveness to the TF.

An alternative approach to transcriptional division of selection genes would be to split the individual ORFs encoding the selection genes to form individually unfunctional heteromultimers as demonstrated in E. coli (Schmidt et al., 2012). At a cost of modularity however, such approaches require that the splitting points of each individual selection gene are developed. For use in pathway construction, detailed 27 
characterization of false-positive ratios in transformation is also important to understand the risks for picking these. Still, split TF-based divisible selection could be combined with such approaches to yield more co-dependent selection units. Alternative to transcriptional splits, longer nutrient biosynthesis pathways could be utilized for co-dependent selection, e.g. by building up selection upon several uracil biosynthesis genes. The disadvantage of such approaches, however, would be less flexibility and the requirement for pre-adapting strains, which limits strain compatibility with existing selection procedures.

By depending on split TF reconstitution, it may further be possible to break down the different modules to allow additional independent DNA fragments to be selected under the same phenotype. For CEN/ARS-based propagation however, the limit for stable maintenance may lie below five plasmids per strain (Futcher and Carbon, 1986). This thus favors chromosomal integration for multiple gene introductions. Similarly constraining could be the co-transformation efficiency or number of possible TF heteromers. The split of phage T7 RNA polymerase into multiple units (Segall - Shapiro et al., 2014) is e.g. of relevance for future E. coli systems. High specificity of such DNA and protein interactions should enable orthogonal use of multiple co-selecting modules, i.e. through further co-dependent hybrid TFs, which independently control different selection gene ORFs. Such orthogonally divided selections could possibly extend the number of gene introductions possible before selection gene recycling. 
New modular selection approaches that rethink selection are likely to significantly aid the speed of multi-gene evaluation. Introduction strategies such as the homologous recombination-guided DNA assembler method (Shao et al., 2009) provides advantages in terms of speed, but reliance on homologous recombination requires absence of interfering recombination-prone sequences. Recent gene editing methods relying on clustered regularly interspaced short palindromic repeats (CRISPRs) are also likely to help speed up cell factory development (DiCarlo et al., 2013; Jakočiūnas et al., 2015), especially if off-target effects or intellectual property concerns (Sherkow, 2015) are not significant or relevant. Selection schemes further have metabolic engineering applications within synthetic screens and other highthroughput assays (Dietrich et al., 2010).

Finally, divisible selection acts as a multi-component AND gate in the sense that all modules are required to transmit the signal (of DNA uptake in this case). Since selection is a powerful method for enhancing multi-component screening, it is possible that the general split hybrid TF network could take other applications, e.g. adapted to other synthetic signal-processing schemes requiring AND logics.

In conclusion, a divisible selection concept based on split hybrid TFs was developed to extend the single utility of selection genes to three. Such systems could be particularly well suited for providing combinatorial flexibility when operating with centromeric plasmids. As shown, the concept could also be used for utilizing the benefits of chromosomal gene integration. 


\section{Competing interests}

The authors declare no competing interests.

\section{Author contributions}

PR and MOAS conceived the study. NMP and PR performed the experiments. PR, NMP and MOAS wrote the manuscript.

\section{Acknowledgements}

The authors wish to thank Irina Borodina for providing the plasmids pCfB393, pCfB394 and pCfB395. The research leading to these results has received funding from the Novo Nordisk Foundation and from the European Union Seventh Framework Programme (FP7-KBBE-2013-7-single-stage) under grant agreement no. 613745, Promys. The funding sources had no involvement in the conduct of the research or the preparation of the article.

\section{References}

Bornscheuer, U.T., Huisman, G.W., Kazlauskas, R.J., Lutz, S., Moore, J.C., Robins, K., 2012. Engineering the third wave of biocatalysis. Nature 485, 185-94. doi:10.1038/nature11117

Boyle, P.M., Silver, P. a, 2012. Parts plus pipes: synthetic biology approaches to metabolic engineering. Metab. Eng. 14, 223-32. doi:10.1016/j.ymben.2011.10.003

Chen, Y., Partow, S., Scalcinati, G., Siewers, V., Nielsen, J., 2012. Enhancing the copy number of episomal plasmids in Saccharomyces cerevisiae for improved 
protein production. FEMS Yeast Res. 12, 598-607. doi:10.1111/j.15671364.2012.00809.x

Clarke, L., Carbon, J., 1985. The structure and function of yeast centromeres. Annu. Rev. Genet. 19, 29-55. doi:10.1146/annurev.ge.19.120185.000333

Da Silva, N. a, Srikrishnan, S., 2012. Introduction and expression of genes for metabolic engineering applications in Saccharomyces cerevisiae. FEMS Yeast Res. 12, 197-214. doi:10.1111/j.1567-1364.2011.00769.x

DiCarlo, J.E., Norville, J.E., Mali, P., Rios, X., Aach, J., Church, G.M., 2013. Genome engineering in Saccharomyces cerevisiae using CRISPR-Cas systems. Nucleic Acids Res. 41, 4336-43. doi:10.1093/nar/gkt135

Dietrich, J.A., McKee, A.E., Keasling, J.D., 2010. High-Throughput Metabolic Engineering: Advances in Small-Molecule Screening and Selection. Annu. Rev. Biochem. doi:10.1146/annurev-biochem-062608-095938

Erhart, E., Hollenberg, C.P., 1983. The presence of a defective LEU2 gene on 2?? DNA recombinant plasmids of Saccharomyces cerevisiae is responsible for curing and high copy number. J. Bacteriol. 156, 625-635.

Futcher, B., Carbon, J., 1986. Toxic effects of excess cloned centromeres. Mol. Cell. Biol. 6, 2213-2222. doi:10.1128/MCB.6.6.2213.Updated

Genee, H.J., Bonde, M.T., Bagger, F.O., Jespersen, J.B., Sommer, M.O.A., Wernersson, R., Olsen, L.R., 2014. Software-Supported USER Cloning Strategies for Site-Directed Mutagenesis and DNA Assembly. ACS Synth. Biol. doi:10.1021/sb500194z

Gibson, D.G., Glass, J.I., Lartigue, C., Noskov, V.N., Chuang, R.-Y., Algire, M. a, Benders, G. a, Montague, M.G., Ma, L., Moodie, M.M., Merryman, C., Vashee, S., Krishnakumar, R., Assad-Garcia, N., Andrews-Pfannkoch, C., Denisova, E. a, Young, L., Qi, Z.-Q., Segall-Shapiro, T.H., Calvey, C.H., Parmar, P.P., Hutchison, C. a, Smith, H.O., Venter, J.C., 2010. Creation of a bacterial cell controlled by a chemically synthesized genome. Science 329, 52-6. doi:10.1126/science.1190719

Gietz, R.D., Schiestl, R.H., 2007. High-efficiency yeast transformation using the LiAc/SS carrier DNA/PEG method. Nat. Protoc. 2, 31-4. doi:10.1038/nprot.2007.13

Hegemann, J.H., Heick, S.B., 2011. Strain Engineering. Methods in Molecular Biology 765. doi:10.1007/978-1-61779-197-0

Herrmann, C., Horn, G., Spaargaren, M., Wittinghofer, a, 1996. Differential interaction of the ras family GTP-binding proteins H-Ras, Rap1A, and R-Ras with the putative effector molecules Raf kinase and Ral-guanine nucleotide exchange factor. J. Biol. Chem. 271, 6794-800.

Jakočiūnas, T., Bonde, I., Herrgård, M., Harrison, S.J., Kristensen, M., Pedersen, L.E., Jensen, M.K., Keasling, J.D., 2015. Multiplex metabolic pathway engineering using CRISPR/Cas9 in Saccharomyces cerevisiae. Metab. Eng. 28, 213-222. doi:10.1016/j.ymben.2015.01.008

Jensen, N.B., Strucko, T., Kildegaard, K.R., David, F., Maury, J., Mortensen, U.H., Forster, J., Nielsen, J., Borodina, I., 2013. EasyClone: method for iterative chromosomal integration of multiple genes in Saccharomyces cerevisiae. FEMS Yeast Res. 1-11. doi:10.1111/1567-1364.12118 
Keasling, J.D., 2012. Synthetic biology and the development of tools for metabolic engineering. Metab. Eng. 14, 189-95. doi:10.1016/j.ymben.2012.01.004

Mead, D.J., Gardner, D.C.J., Oliver, S.G., 1986. The yeast 2 ? plasmid: strategies for the survival of a selfish DNA. MGG Mol. Gen. Genet. 205, 417-421. doi:10.1007/BF00338076

Mikkelsen, M.D., Buron, L.D., Salomonsen, B., Olsen, C.E., Hansen, B.G., Mortensen, U.H., Halkier, B.A., 2012. Microbial production of indolylglucosinolate through engineering of a multi-gene pathway in a versatile yeast expression platform. Metab. Eng. 14, 104-111. doi:10.1016/j.ymben.2012.01.006

Mitchell, A.P., 1994. Control of Meiotic Gene Expression in Saccharomyces cerevisiae. Microbiol. Mol. Biol. Rev. 58.

Naesby, M., Nielsen, S.V., Nielsen, C.A., Green, T., Tange, T.O., Simón, E., Knechtle, P., Hansson, A., Schwab, M.S., Titiz, O., Folly, C., Archila, R.E., Maver, M., van Sint Fiet, S., Boussemghoune, T., Janes, M., Kumar, a S.S., Sonkar, S.P., Mitra, P.P., Benjamin, V.A.K., Korrapati, N., Suman, I., Hansen, E.H., Thybo, T., Goldsmith, N., Sorensen, A.S., 2009. Yeast artificial chromosomes employed for random assembly of biosynthetic pathways and production of diverse compounds in Saccharomyces cerevisiae. Microb. Cell Fact. 8, 45. doi:10.1186/1475-2859-8-45

Nielsen, C., Folly, C., Hatsch, A., Molt, A., Schröder, H., O Connor, S.E., Naesby, M., 2014. The important ergot alkaloid intermediate chanoclavine-I produced in the yeast. Microb. Cell Fact. 13, 95. doi:10.1186/s12934-014-0095-2

Nielsen, J., Larsson, C., van Maris, A., Pronk, J., 2013. Metabolic engineering of yeast for production of fuels and chemicals. Curr. Opin. Biotechnol. 24, 398404. doi:10.1016/j.copbio.2013.03.023

Nørholm, M.H.H., 2010. A mutant Pfu DNA polymerase designed for advanced uracil-excision DNA engineering. BMC Biotechnol. 10, 21. doi:10.1186/14726750-10-21

Regenberg, B., Hansen, J., 2000. GAP1, a novel selection and counter-selection marker for multiple gene disruptions in Saccharomyces cerevisiae. Yeast 16, 1111-9. doi:10.1002/1097-0061(20000915)16:12<1111::AIDYEA611>3.0.CO;2-3

Rugbjerg, P., Naesby, M., Mortensen, U.H., Frandsen, R.J., 2013. Reconstruction of the biosynthetic pathway for the core fungal polyketide scaffold rubrofusarin in Saccharomyces cerevisiae. Microb. Cell Fact. 12, 31. doi:10.1186/1475-285912-31

Schmidt, C.M., Shis, D.L., Nguyen-Huu, T.D., Bennett, M.R., 2012. Stable maintenance of multiple plasmids in E. coli using a single selective marker. ACS Synth. Biol. 1, 445-50. doi:10.1021/sb3000589

Segall-Shapiro, T., Meyer, A., Ellington, A.D., Sontag, E.D., Voigt, C. a, 2014. A "resource allocator" for transcription based on a highly fragmented T 7 RNA polymerase. Mol. Syst. Biol. Biol. 10, 1-15.

Shao, Z., Zhao, H., Zhao, H., 2009. DNA assembler, an in vivo genetic method for rapid construction of biochemical pathways. Nucleic Acids Res. 37, e16. doi:10.1093/nar/gkn991 
Sherkow, J.S., 2015. Law, history and lessons in the CRISPR patent conflict. Nat. Biotechnol. 33, 256-257. doi:10.1038/nbt.3160

Siddiqui, M.S., Choksi, A., Smolke, C.D., 2014. A system for multi-locus chromosomal integration and transformation-free selection marker rescue. FEMS Yeast Res. doi:10.1111/1567-1364.12210

Siddiqui, M.S., Thodey, K., Trenchard, I., Smolke, C.D., 2011. Advancing Secondary Metabolite Biosynthesis in Yeast with Synthetic Biology Tools. FEMS Yeast Res. 12, 144-170. doi:10.1111/j.1567-1364.2011.00774.x

Sikorski, R., Hieter, P., 1989. A system of shuttle vectors and yeast host strains designed for efficient manipulation of DNA in Saccharomyces cerevisiae. Genetics 122, 19-27.

Solis-Escalante, D., Kuijpers, N.G. a, Bongaerts, N., Bolat, I., Bosman, L., Pronk, J.T., Daran, J.-M., Daran-Lapujade, P., 2013. amdSYM, a new dominant recyclable marker cassette for Saccharomyces cerevisiae. FEMS Yeast Res. 13, 126-39. doi:10.1111/1567-1364.12024

Tyo, K.E., Alper, H.S., Stephanopoulos, G.N., 2007. Expanding the metabolic engineering toolbox: more options to engineer cells. Trends Biotechnol. 25, 1327. doi:10.1016/j.tibtech.2007.01.003

Vidal, M., Brachmann, R.K., Fattaey, a, Harlow, E., Boeke, J.D., 1996. Reverse twohybrid and one-hybrid systems to detect dissociation of protein-protein and DNA-protein interactions. Proc. Natl. Acad. Sci. U. S. A. 93, 10315-20.

Wingler, L.M., Cornish, V.W., 2011. Reiterative Recombination for the in vivo assembly of libraries of multigene pathways. Proc. Natl. Acad. Sci. U. S. A. 108, 15135-40. doi:10.1073/pnas.1100507108

Zhang, A.P.P., Pigli, Y.Z., Rice, P. a, 2010. Structure of the LexA-DNA complex and implications for SOS box measurement. Nature 466, 883-6.

doi:10.1038/nature09200 
Supplementary material for:

\section{Flexible metabolic pathway construction using modular and divisible selection gene regulators}

Authors:

Peter Rugbjerg, Nils Myling-Petersen, Morten O. A. Sommer

Table of Contents

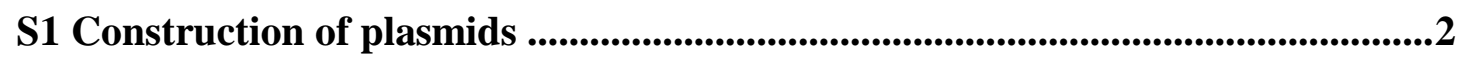

S2 Evaluation of alternative $d s 1$ modules ...........................................................

S3 Stability of four CEN6-propagated plasmids.................................................9

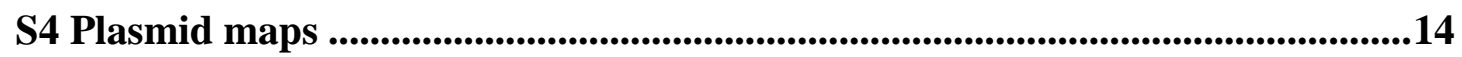

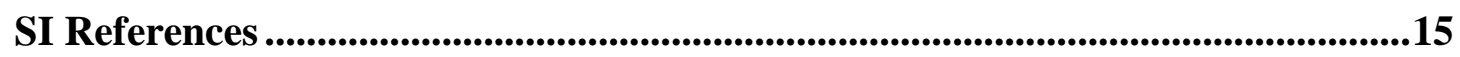




\section{S1 Construction of plasmids}

Plasmids were all assembled from individual PCR fragments. Table S1 lists the PCR fragment composition (by primers and DNA template) leading to the indicated plasmid. Further detail on PCR templates is given in Table S2, while the respective oligonucleotide sequences are specified in Table S3.

Table S1 PCR fragments used to assemble the listed plasmids using the indicated primer pairs and DNA template. Sequences of linear DNA fragments used as template are given in text below, and overview of template plasmids is given in Table S2. All plasmids were assembled through uracil excision cloning with the exception of pDS2-aurZ.

\begin{tabular}{|c|c|c|}
\hline Plasmid ID & Primer pair & Template \\
\hline \multirow[t]{5}{*}{ pDS1 U } & P312/P313 & pRS416 \\
\hline & P273/P258 & pUG72 \\
\hline & P305/P56 & S. cerevisiae gDNA \\
\hline & P55/P302 & SPO13 hybrid DNA fragment \\
\hline & P255/ID399 & pUG72 \\
\hline \multirow[t]{2}{*}{ pDS1 H } & P285/P55 & pDS1 U \\
\hline & P205/P284 & S. cerevisiae gDNA \\
\hline \multirow[t]{5}{*}{ pDS2 } & P313/P312 & pRS416 \\
\hline & P261/P273 & pUG75 \\
\hline & P192B/P192 & E. coli gDNA \\
\hline & P193/P283 & pEXP32 \\
\hline & P260/ID399 & pUG75 \\
\hline \multirow[t]{5}{*}{ pDS3 } & P312/P313 & pRS416 \\
\hline & P261/P273 & pUG75 \\
\hline & P42/P112 & VP16 AD DNA fragment \\
\hline & P202/P259 & pEXP22 \\
\hline & P260/ID399 & pUG75 \\
\hline \multirow[t]{3}{*}{ pS1.2 } & P55/P267 & pDS1 U \\
\hline & P252/P273 & pUG72 \\
\hline & ID399/P255 & pUG72 \\
\hline
\end{tabular}




\begin{tabular}{|c|c|c|}
\hline & P271/P272 & pRS416 \\
\hline \multirow[t]{2}{*}{ pS1.3 } & P273/P302 & pDS1 U \\
\hline & P255/P272 & $\mathrm{pS} 1.2$ \\
\hline \multirow{2}{*}{$\begin{array}{l}\text { pDS1U- } \\
\text { PKS12 }\end{array}$} & P273/ID399 & pDS1 U \\
\hline & P312/P313 & pRS416-PKS12 \\
\hline \multirow{2}{*}{$\begin{array}{l}\text { pDS2-aurz } \\
\text { Gibson } \\
\text { assembly }\end{array}$} & P273/ID399 & pDS2 \\
\hline & Smal-digested plasmid & pRS414-aurZ \\
\hline \multirow[t]{2}{*}{ pDS3-aurJ } & P273/ID399 & pDS3 \\
\hline & P312/P313 & pRS415-aurJ \\
\hline \multirow[t]{2}{*}{ pDS1Um } & P116/P119 & pDS1U \\
\hline & P117/P118 & pESC-HIS \\
\hline \multirow[t]{2}{*}{ pDS2m } & P116/P119 & pDS2 \\
\hline & P117/P118 & pESC-HIS \\
\hline \multirow[t]{2}{*}{ pDS3m } & P116/P119 & pDS3 \\
\hline & P117/P118 & pESC-HIS \\
\hline \multirow[t]{2}{*}{ pDS1U-X2 } & P468/ID399 & pDS1U \\
\hline & P467/P469 & pCfB393 \\
\hline \multirow[t]{2}{*}{ pDS2-X3 } & P468/ID399 & pDS2 \\
\hline & P467/P469 & pCfB394 \\
\hline \multirow[t]{2}{*}{ pDS3-X4 } & P468/ID399 & pDS3 \\
\hline & P467/P469 & pCfB395 \\
\hline
\end{tabular}

Table S2 Plasmids used as PCR template for plasmid construction (listed in Table S1) and alternative ds1 plasmids evaluated in S2.

\begin{tabular}{|c|c|c|}
\hline Plasmid & Features (not complete) & Reference \\
\hline pDS1.2U & $\mathrm{pUC}$ origin, $\mathrm{f} 1, \mathrm{ARS} / \mathrm{CEN}, a m p R, 8 \mathrm{op}_{\mathrm{lexA}}-\mathrm{p}_{\mathrm{SPO} 13}-U R A 3$ & This study \\
\hline pDS1.3U & $\mathrm{pUC}$ origin, f1, ARS/CEN, ampR, $4 \mathrm{op}_{\mathrm{lexA}}-\mathrm{p}_{\mathrm{SPO} 13}-$ KIURA3 & This study \\
\hline pUG72 & pUC origin, loxP- KIURA3 $-K I U R A 3-\mathrm{t}_{\mathrm{KIURA}}-$-loxP, $a m p R$ & (Hegemann and Heick, 2011) \\
\hline pUG75 & pUC origin, loxP- $\mathrm{p}_{\mathrm{AgTEF} 1}-h p h M X-\mathrm{t}_{\mathrm{AgTEF} 1}-\mathrm{loxP}, a m p R$ & (Hegemann and Heick, 2011) \\
\hline pEXP22 & RalGDS-GAL4AD, pUC origin, f1, ARS/CEN, TRP1, ampR & Life Technologies - Proquest \\
\hline pEXP32 & Krev1-GAL4DBD, pUC origin, f1, ARS/CEN, LEU2, ampR & Life Technologies - Proquest \\
\hline pRS413 & pUC origin, $\mathrm{f} 1, \mathrm{ARS} / \mathrm{CEN}, \mathrm{HIS3}, a m p R$ & (Sikorski and Hieter, 1989) \\
\hline pRS414 & $\mathrm{pUC}$ origin, $\mathrm{f} 1, \mathrm{ARS} / \mathrm{CEN}, \mathrm{TRP} 1, a m p R$ & (Sikorski and Hieter, 1989) \\
\hline pRS415 & pUC origin, $\mathrm{f} 1, \mathrm{ARS} / \mathrm{CEN}, \mathrm{LEU} 2, a m p R$ & (Sikorski and Hieter, 1989) \\
\hline pRS416 & pUC origin, $\mathrm{f} 1, \mathrm{ARS} / \mathrm{CEN}, \mathrm{URA3}, \mathrm{ampR}$ & (Sikorski and Hieter, 1989) \\
\hline
\end{tabular}




\begin{tabular}{|c|c|c|}
\hline pRS416-PKS12 & $\mathrm{p}_{\mathrm{CUP} 1}-P K S 12-\mathrm{t}_{\mathrm{ADH} 1}, \mathrm{pUC}$ origin, $\mathrm{f} 1, \mathrm{ARS} / \mathrm{CEN}$, URA3, $a m p R$ & (Rugbjerg et al., 2013) \\
\hline pRS414-aurZ & $\mathrm{p}_{\mathrm{TEF1} 1}$-aurZ- $\mathrm{t}_{\mathrm{ENO} 2}, \mathrm{pUC}$ origin, $\mathrm{f1}, \mathrm{ARS} / \mathrm{CEN}, T R P 1, a m p R$ & (Rugbjerg et al., 2013) \\
\hline pRS415-aurJ & $\mathrm{p}_{\mathrm{GPD} 1}$-aurJ-t $\mathrm{t}_{\mathrm{CYC1}}, \mathrm{pUC}$ origin, $\mathrm{f1}, \mathrm{ARS} / \mathrm{CEN}$, LEU2, ampR & (Rugbjerg et al., 2013) \\
\hline pESC-HIS & 2-micron, HIS3, $a m p R$ & Agilent Technologies \\
\hline pCfB393 & $\mathrm{X}-2$ targeting flanks, pTEF-CFP-tADH1, $a m p R$ & (Jensen et al., 2013) \\
\hline pCfB394 & $\mathrm{X}-3$ targeting flanks, pTEF-RFP-tADH1, ampR & (Jensen et al., 2013) \\
\hline pCfB395 & $\mathrm{X}$-4 targeting flanks, pTEF-YFP-tADH1, $a m p R$ & (Jensen et al., 2013) \\
\hline
\end{tabular}


Nucleotide sequence of SPO13 hybrid DNA fragment:

>SPO13 hybrid DNA fragment

TTCCGACCTGCAGTACTGTATGTACATACAGTACTGTATGTACATACAGTACTGCAGGCATGCAAGCT

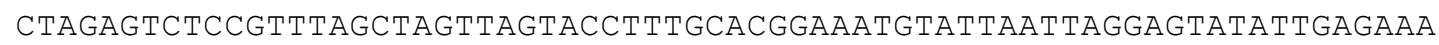

TAGCCGCCGACAAAAAGGAAGTCTCATAAAAGTGTCTAACAGACAATTAGCGCAATAAGAAGAAAGAA

AACGGATTGAAGTTGAGTCGAGAATAATT

Nucleotide sequence encoding VP16 AD, synthesized by Life Technologies GeneArt:

$>$ VP16 AD DNA fragment

TCGACGGCCCCCCCGACCGATGTCAGCCTGGGGGACGAGCTCCACTTAGACGGCGAGGACGTGGC GAT GGCGCATGCCGACGCGCTAGACGATTTCGATCTGGACATGTTGGGGGACGGGGATTCCCCGGGGCCGG GATTTACCCCCCACGACTCCGCCCCCTACGGCGCTCTGGATATGGCCGACTTCGAGTTTGAGCAGATG TTTACCGATGCCCTTGGAATGACGAGTACGGTGGG

Table S3 Sequence of oligonucleotides used in the study

\begin{tabular}{|l|l|}
\hline Primer ID & Oligonucleotide sequence (5'-) \\
\hline P35 & GACAGCTTCCTGATCGGAAGG \\
\hline P42 & AACATAUGCCCAAGAAGAAGCGG \\
\hline P55 & AATTATTCUCGACTCAACTTCAATC \\
\hline P56 & AGAATAATUATGTCGAAAGCTACATATAAGGAA \\
\hline P111 & AGCGGAAGGUCAAGCTTTCGACGGCCCCC \\
\hline P112 & ACCCACCGUACTCGTCAATTCC \\
\hline P116 & AGGTGGCACUTTTCGGG \\
\hline P117 & AGTGCCACCUGAACGAAG \\
\hline P118 & ATGGTTTCUTAGATGATCCAATATC \\
\hline P119 & AGAAACCAUTATTATCATGACATTAAC \\
\hline P191 & AGCGGAAGGCTCGAGCATGAAAGCGTTAACGGCCAG \\
\hline P192 & AGCCAGUCGCCGTTGCG \\
\hline
\end{tabular}




\begin{tabular}{|c|c|}
\hline P192B & AACATAUGCCCAAGAAGAAGCGGAAGGTCTCGAGCATGAAAGCGTTAACGGCCAG \\
\hline P193 & АСTGGCUGAGGTCGAATCAAACAAGTTTG \\
\hline P202 & ATTGTCGAAUCAAACAAGTTTGTA \\
\hline P205 & AGAATAATUATGACAGAGCAGAAAGCC \\
\hline P230 & АСCCTTTCUCCGCTTCTTTAGGATGAAGTCATAGTTGGC \\
\hline $\mathrm{P} 252$ & ATTATGUCCACAAAATCATATACCA \\
\hline P255 & ACGAGCUTTCGAGAACCC \\
\hline P258 & AGCTTAUACAGGAAACTTAATAGAACAAATC \\
\hline P259 & ACCGCTUCTTTAGGATG \\
\hline P260 & AAGCGGUAACTCGAGGACAATAAAAAGA \\
\hline P261 & ATATGTUCTTGTTTATGTTCGGATGTG \\
\hline P267 & AGCTCGUTCCGACCTGCAGTACTG \\
\hline P271 & ACCCAAUGCATCAGGAAATTGTAAACG \\
\hline $\mathrm{P} 272$ & AAGCTGUGGTATGGTGCA \\
\hline P273 & ACAGCTUTCGACAACCCTTAATATAACTTC \\
\hline P283 & ACCGCTUCTAGAGCAGCAGACATGATTTC \\
\hline P284 & ATTACAUAAGAACACCTTTGGTG \\
\hline P285 & ATGTAAUTATACAGGAAACTTAATAGAACAAATC \\
\hline P302 & AGCTCGUCTGTATATATATACAGATCTGATATATATACAGCGTTCCGACCTGCAGTACTG \\
\hline P377 & ACTGAGAUACCTACAGCGTGAGCTAT \\
\hline ID399 & ATTGGGUGCATAGGCCACTAGTGGATCTG \\
\hline P467 & ACGCGAUCTTCGAGCGTCCCAAAACC \\
\hline P468 & ATCGCGUCATAACAGCTTTCGACAACCC \\
\hline P469 & ACCCAAUTCGCCCTATAGTGAGTCG \\
\hline
\end{tabular}




\section{S2 Evaluation of alternative $d s 1$ modules}

To investigate a possible advantage of utilizing a heterologous nucleotide sequence of $U R A 3$, we designed a mutant $d s 1$ module with a heterologous selection gene ORF the K. lactis URA3 (ds1.3-KIURA3), which has limited identity to potential hostinactivated URA3 genes in S. cerevisiae laboratory strains.

At prolonged incubation times following transformation $\left(30{ }^{\circ} \mathrm{C}\right.$ for 6 days), this plasmid alone however permitted formation of small false-positive colonies (Fig S1). We therefore tested the $S$. cerevisiae URA3 in a new construct to limit these falsepositive colonies and possibly improve true positives by simultaneously introducing extra high-affinity LexA binding sites. Together with $d s 2$ and $d s 3$, the $d s 1.2$ module (pDS1.2U) produced an average of 126 transformants following three days incubation and alone 2 false-positive transformants on average, while the second $d s 1.3$ module (pDS1.3U) with two additional LexA binding sites and S. cerevisiae URA3 generated the same average of false- and true-positive colonies (Fig. S1). Interestingly however, the use of URA3 from $S$. cerevisiae did not lead to elevated false-positive colony formation at prolonged incubation times. This indicated a possible lower background expression or activity of this URA3 enzyme and also that the few false-positive colonies did not result from recombination at the inactivated ura3 locus of the transformed CEN.PK2-1C strain. 


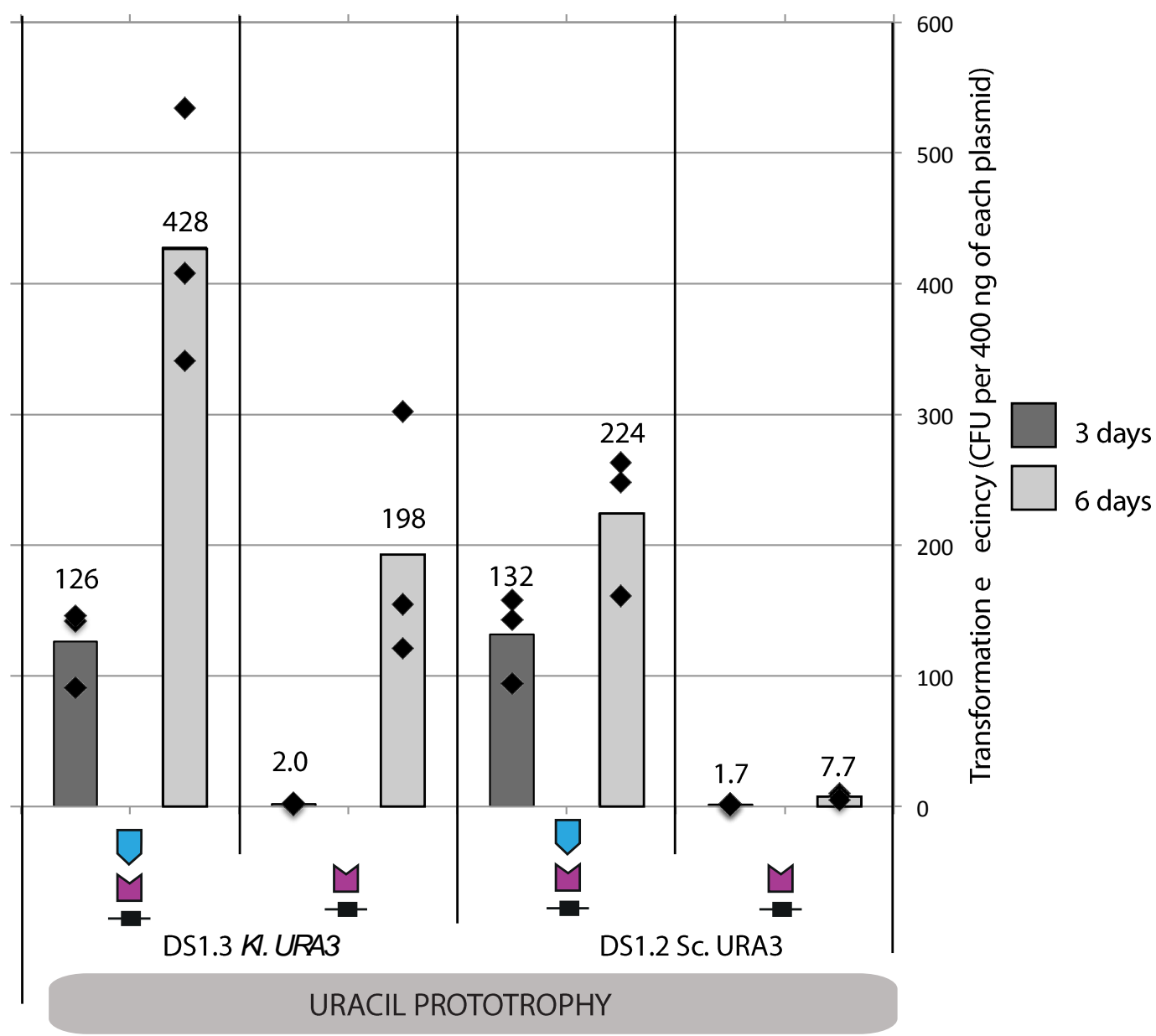

Figure S1. Characterization of $d s 1$ modules at prolonged incubation. Transformation efficiencies (average CFU per $400 \mathrm{ng}$ of each plasmid) in S. cerevisiae CEN.PK2-1C transformed with incomplete or complete divisible selection modules $(d s 1, d s 2$ and $d s 3)$ under selection on SC -ura. CFUs counted following three or six days at $30{ }^{\circ} \mathrm{C}$. Black points show values from individual replicate transformations $(\mathrm{n}=3)$. 


\section{S3 Stability of four CEN6-propagated plasmids}

The viability of strains propagating four CEN6/ARS plasmids in a $S$. cerevisiae CEN.PK2-1C strain was assayed in comparison to strains transformed with respectively zero and one CEN6/ARS plasmid (Table S4). To test if a cost of propagating the number of plasmids was conferred to the strains, their growth rates were first measured. In order to avoid potential influences of the different prototrophic genes on growth rate (Pronk, 2002), which would not be a measure of CEN6/ARS plasmid toxicity, the evaluation of the growth rates was performed in non-selective YPD medium, which would also allow loss of plasmids. Empty plasmids were used to exclude fitness costs associated with expressing various numbers of pathway enzymes. Pre-cultures of the strains grown in selective SC medium were used to inoculate $180 \mu \mathrm{L}$ microtiter cultures in YPD medium, at $30{ }^{\circ} \mathrm{C}$, $300 \mathrm{rpm}$ horizontal shaking (New Brunswick Innova 44R). Their growth rates were calculated by exponential regression of OD600 values versus time obtained in the same range of the exponential growth phase and including at least seven data points. The resulting similar growth rates in non-selective YPD medium (Table S4) indicated that four different CEN6/ARS plasmids did not constitute a significant growth disadvantage in the CEN.PK2-1C strain without selection for plasmid maintenance. Loss of plasmids over time would however occur (Clarke and Carbon, 1985).

Table S4 Growth rate of $S$. cerevisiae CEN.PK2-1C harboring respectively 0,1 and 4 different CEN6/ARS plasmids, in exponential phase, cultured in YPD at $30{ }^{\circ} \mathrm{C}, 300 \mathrm{rpm}$ horizontal sharking $(\mathrm{n}=3)$.

\begin{tabular}{|l|l|l|}
\hline S. cerevisiae strain & Number of & \\
\hline CEN.PK2-1C & plasmids & standard deviation \\
\hline CEN.PK2-1C+pRS413 & 1 & $0.27+/-0.0032$ \\
\hline CEN.PK2-1C + pRS413 + & 4 & $0.26+/-0.0080$ \\
pDS1U, pDS2, pDS3 & & \\
\hline CEN.PK2-1C + pRS413 + & 4 & $0.27+/-0.0061$ \\
\hline
\end{tabular}


The degree of plasmid loss was subsequently indicated through plating of serially diluted spots of a four CEN6/ARS plasmid strain on various, selective SC media (SC, $\mathrm{SC}$-histidine, SC -uracil -histidine) from non-selective YPD cultures grown at $30^{\circ} \mathrm{C}$, for respectively 20 and 30 generations through passing of $15 \mathrm{~mL}$ cultures to fresh medium (Figure S2). Whereas maintenance of only one CEN6/ARS plasmid appeared stable without selection (plated on SC - histidine), a significant number of cells had lost at least one of the four plasmids, as seen when selecting for all simultaneously (SC - histidine, -uracil) (Figure S2). This implies that selection for four plasmids constitutes a negative factor on the growth rate of strains harboring four CEN6/ARS plasmids (overexpression of their respective selection genes could be another factor). In expanding divisible selection concepts beyond three centromeric plasmids, these effects would be important to characterize in depth. 


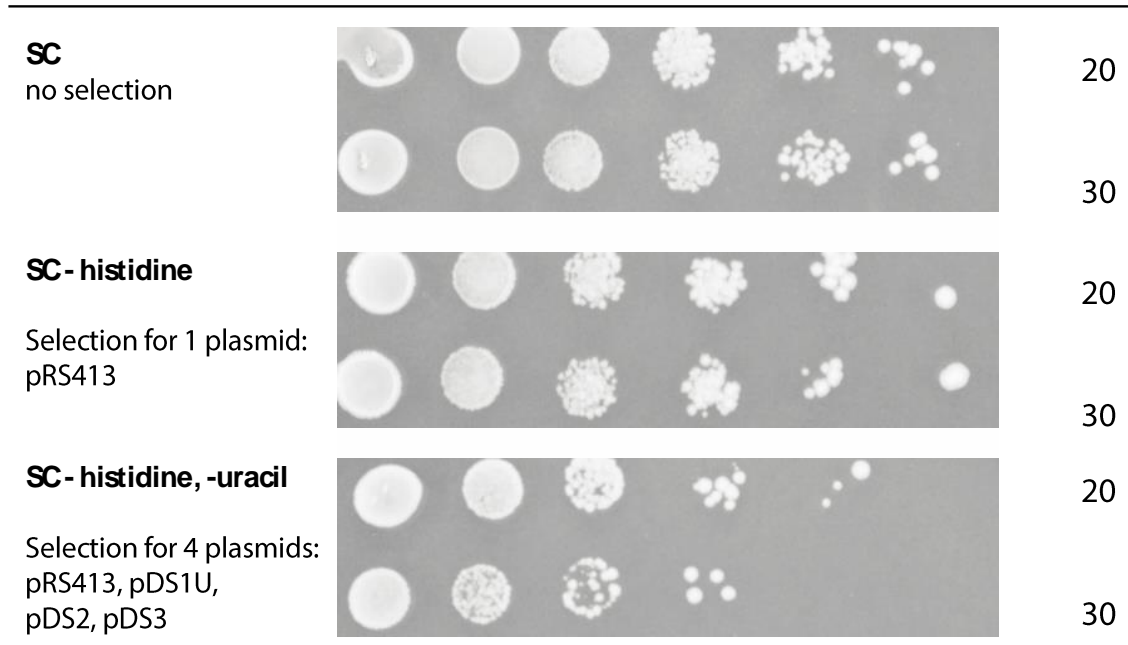

Figure S2 Loss of plasmids following long-term incubation in non-selective medium. 10-fold serial dilution spot assays of $S$. cerevisiae CEN.PK2-1C transformed with four plasmids, on the indicated plates selecting for the number of CEN6/ARS plasmids shown to evaluate the number of colonyforming cells following incubation for the indicated number of generations in non-selective YPD medium. Plates incubated at $30{ }^{\circ} \mathrm{C}$ for 4 days.

The cell morphology in cultures grown in selective SC medium at $30{ }^{\circ} \mathrm{C}$ was finally inspected by microscopy to assess the health of the four-plasmid cells. Visual comparison showed no clear morphological differences nor long filament-like cell structures (Figure S3) as observed in strains with five CEN3/ARS plasmids in the $S$. cerevisiae BF307-10 strain grown in selective YNB medium (Futcher and Carbon, 1986). The size of the cells containing four CEN6/ARS plasmids could however appear slightly larger than of those containing zero. 
A

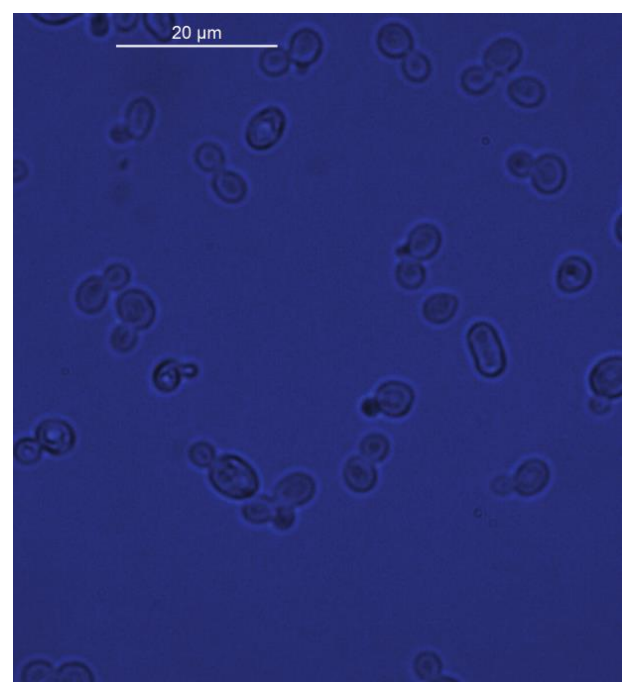

B

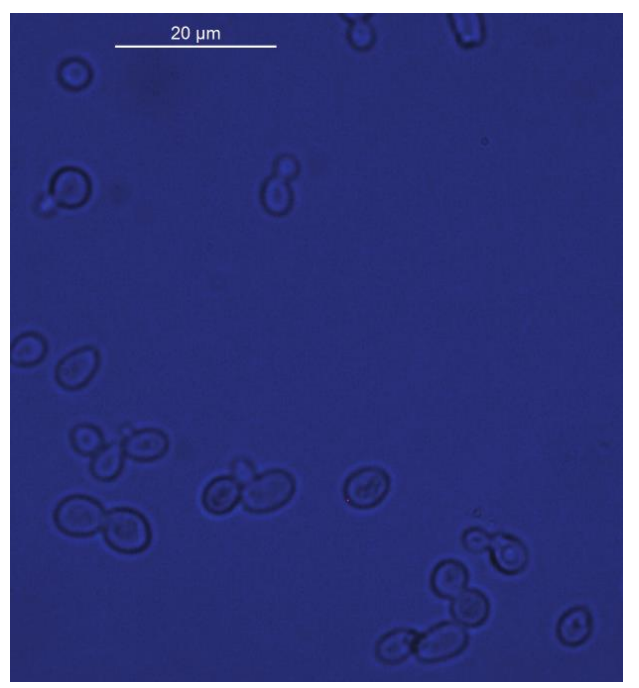

Figure S3 Cell morphology. Exponentially growing $S$. cerevisiae cells in selective SC medium transformed with respectively A) zero CEN6/ARS plasmids and B) four different CEN6/ARS plasmids.

To test the ability to maintain production with a biosynthetic pathway, cultures of divisibly selected rubrofusarin strains (ds-rub) were grown in selective SC medium (uracil, -histidine) for 30 generations and plated on selective plates. The stability of each of the four CEN6/ARS plasmids was then tested in ten randomly picked colonies through PCR of unique elements (Table S5). Specific PCR products from all four plasmids could be detected in all ten colonies. The corresponding ability to maintain production was also indicated by their pigmentation through re-streak of the same ten colonies to plates with induction of the pathway (Figure S4). The yellow nuance of the rubrofusarin pathway precursors (YWA1 and nor-rubrofusarin) however means that the PCR-based evaluation is important to verify maintenance of all plasmids.

Table S5 PCR confirmation of plasmid maintenance in ten colonies of rubrofusarin-pathway S. cerevisiae following 30-generation liquid cultivation. For each plasmid, the oligonucleotide pairs used in PCR are shown with their results.

\begin{tabular}{|l|l|l|}
\hline Plasmid to be verified & Oligonucleotides & Colonies with \\
\hline pRS413-npgA & P35 + P377 & $10 / 10$ \\
\hline
\end{tabular}




\begin{tabular}{|l|l|l|}
\hline pDS1U-PKS12 & P55 + ID399 & $10 / 10$ \\
\hline pDS2-aurZ & P191 + P283 & $10 / 10$ \\
\hline pDS3-aurJ & P111 + P230 & $10 / 10$ \\
\hline
\end{tabular}

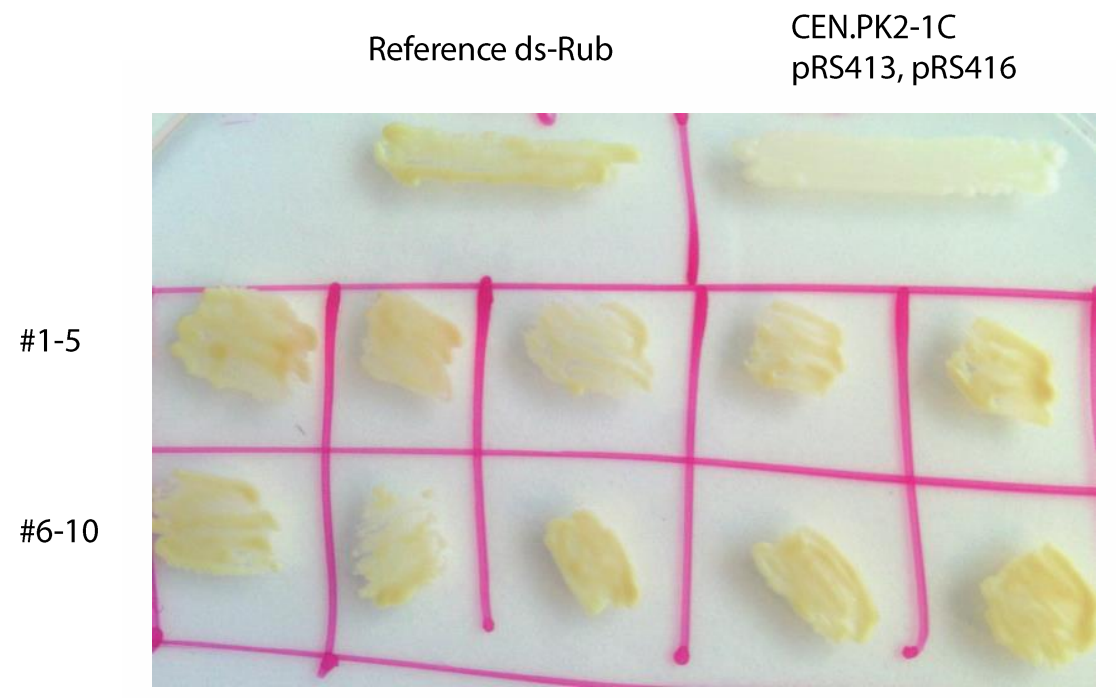

Figure S4 Confirmation of pathway product accumulation of individual colonies picked following long-term culture. Individual colonies streak to $\mathrm{SC}$-uracil, -histidine plates with $100 \mu \mathrm{M} \mathrm{Cu}^{2+}$, incubated for 4 days at $30^{\circ} \mathrm{C}$. Photograph brightness was increased 20 percent. 


\section{S4 Plasmid maps}
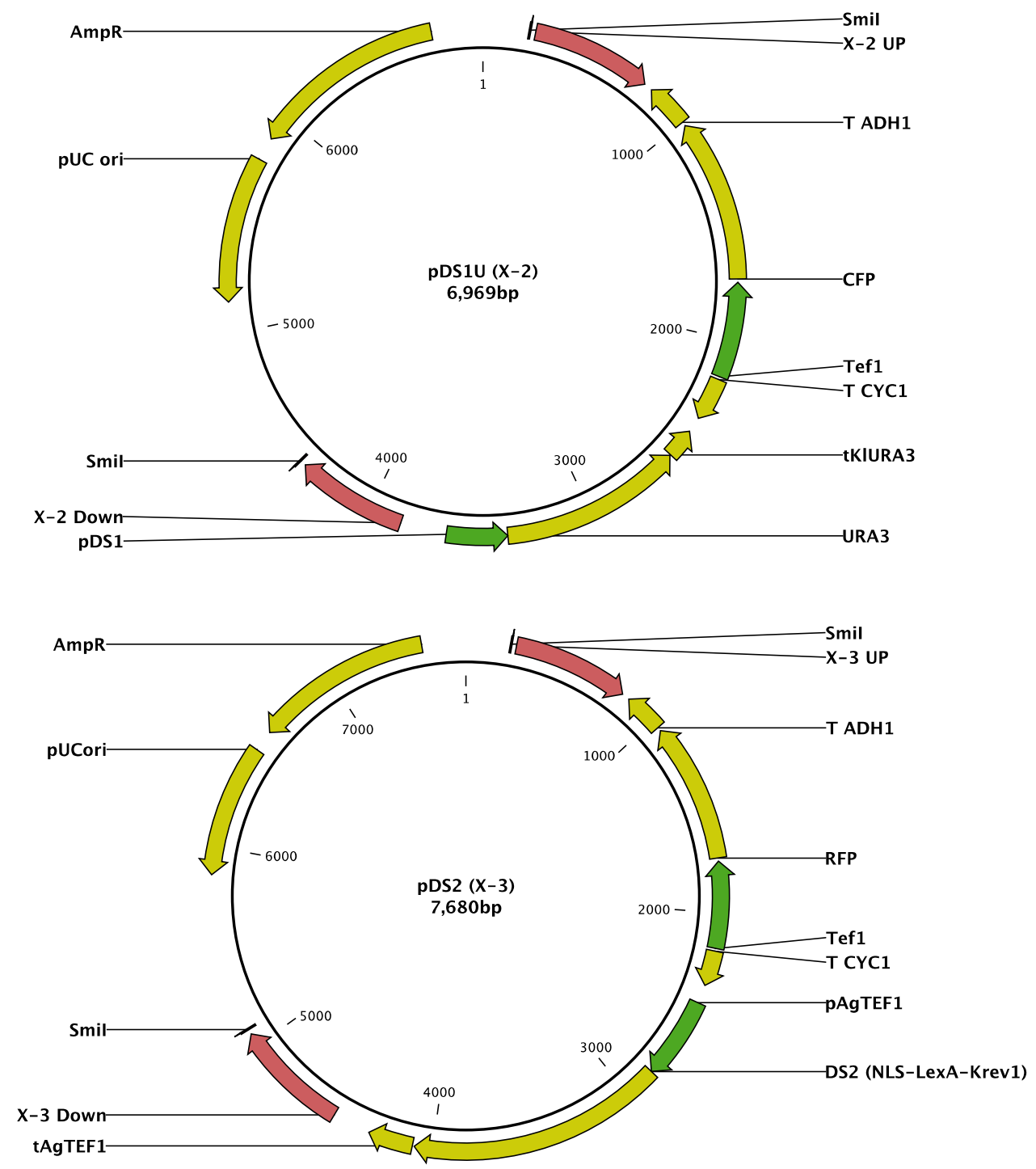


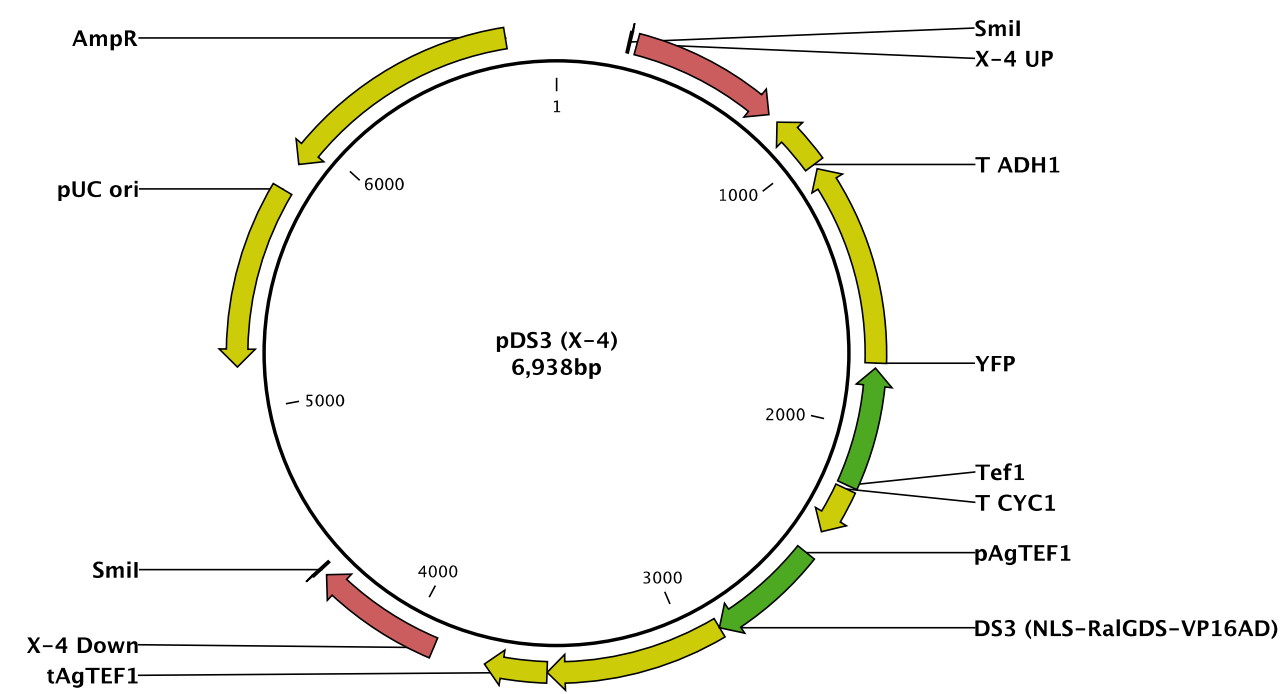

\section{SI References}

Clarke, L., Carbon, J., 1985. The structure and function of yeast centromeres. Annu. Rev. Genet. 19, 29-55. doi:10.1146/annurev.ge.19.120185.000333

Futcher, B., Carbon, J., 1986. Toxic effects of excess cloned centromeres. Mol. Cell. Biol. 6, 2213-2222. doi:10.1128/MCB.6.6.2213.Updated

Hegemann, J.H., Heick, S.B., 2011. Strain Engineering. Methods in Molecular Biology 765. doi:10.1007/978-1-61779-197-0

Jensen, N.B., Strucko, T., Kildegaard, K.R., David, F., Maury, J., Mortensen, U.H., Forster, J., Nielsen, J., Borodina, I., 2013. EasyClone: method for iterative chromosomal integration of multiple genes in Saccharomyces cerevisiae. FEMS Yeast Res. 1-11. doi:10.1111/1567-1364.12118

Pronk, J.T., 2002. Auxotrophic Yeast Strains in Fundamental and Applied Research. Appl. Environ. Microbiol. 68, 2095-2100. doi:10.1128/AEM.68.5.2095

Rugbjerg, P., Naesby, M., Mortensen, U.H., Frandsen, R.J., 2013. Reconstruction of the biosynthetic pathway for the core fungal polyketide scaffold rubrofusarin in Saccharomyces cerevisiae. Microb. Cell Fact. 12, 31. doi:10.1186/1475-285912-31

Sikorski, R.S., Hieter, P., 1989. A System of Shuttle Vectors and Yeast Host Strains Designed for Efficient Manipulation of DNA in Saccharomyces cerevisiae. 